\title{
Le croisement Brahman à Madagascar
}

par H. SERRES, P. CAPITAINE, P. DUBOIS, R. DUMAS ef J. GILIBERT

Le lecteur trouvera ci-après une série de photographies concernant l'artıcle «Le croisement Brahman à Madagascar » paru dans le tome 21, no 4 pages 519-61 qui, pour des raisons techniques, n'ont pu être publiées en même temps que le texte. 


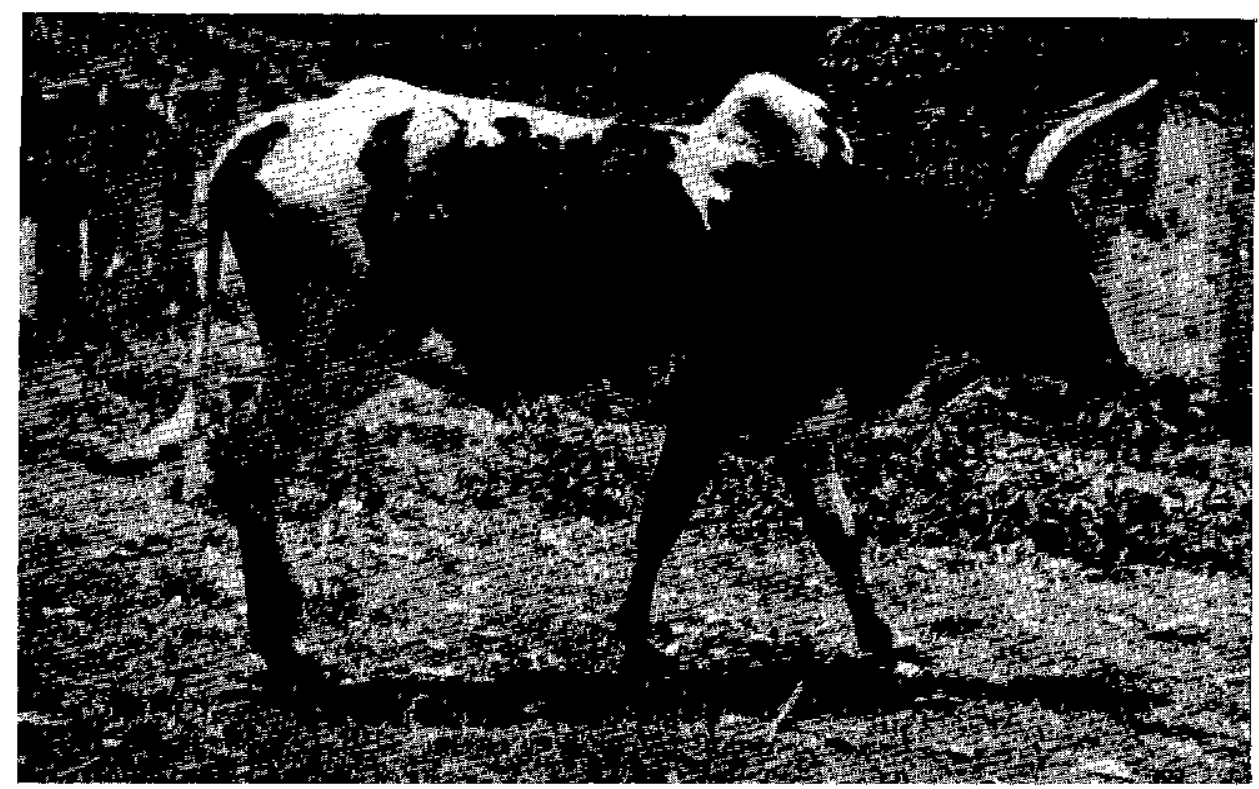

Cliché 1 : Mâle zébu malgache.

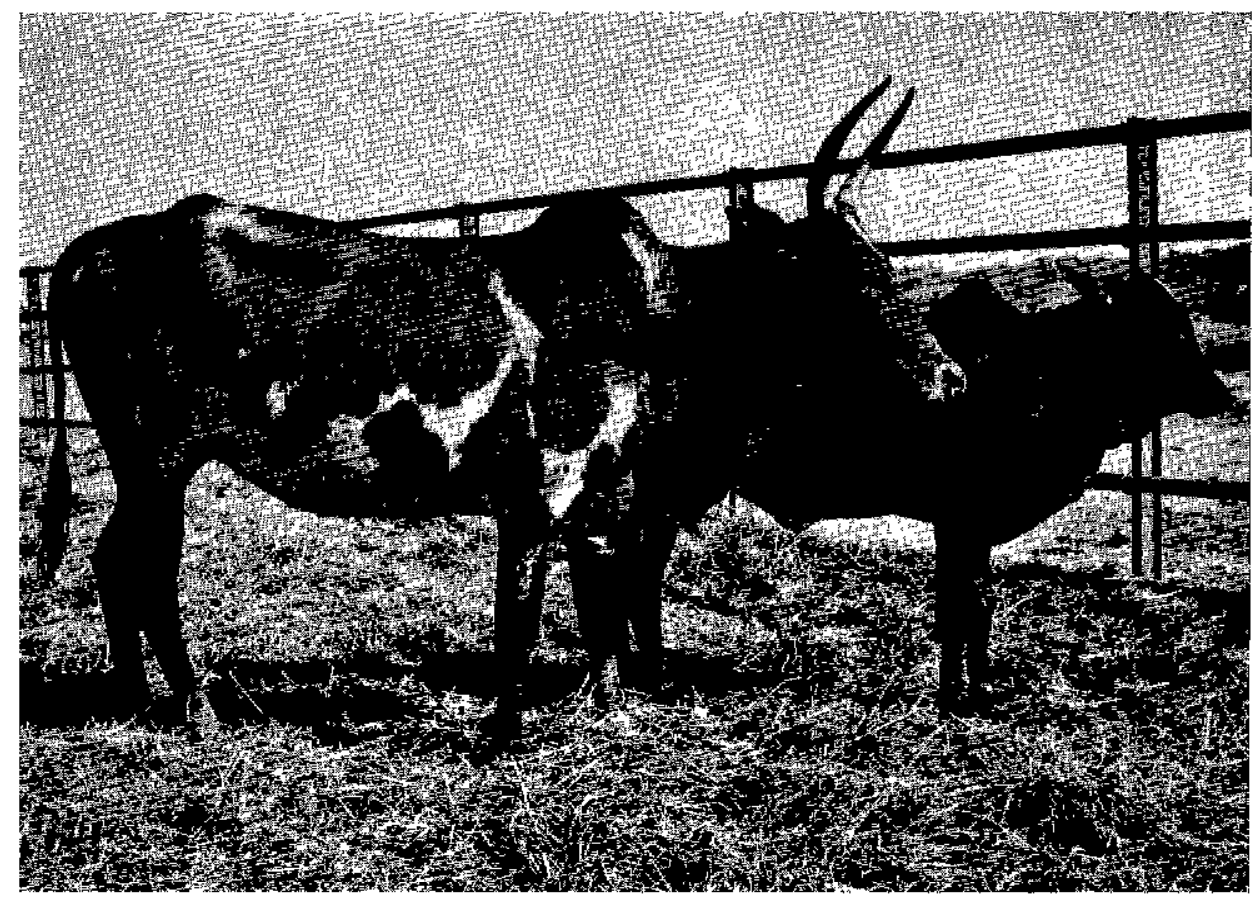

Cliché 2 : Femelle zébu malgache ef son veau métis.

On remarquera la finesse de la tête à profl rectiligne, le bassin très oblique et la musculature faible du train postérieur. 


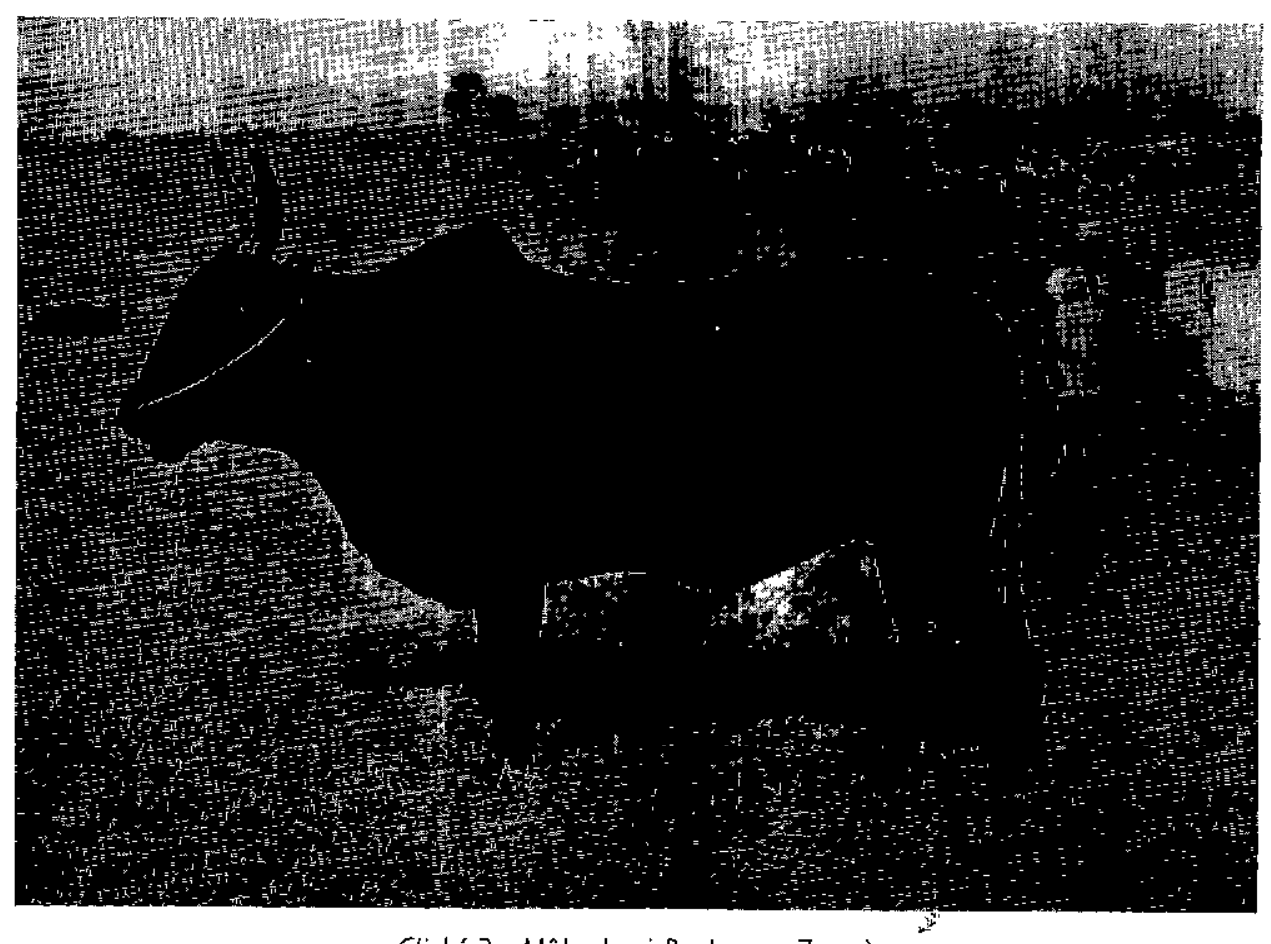

Cliché 3 : Mâle derni-Brahman 7 ans).

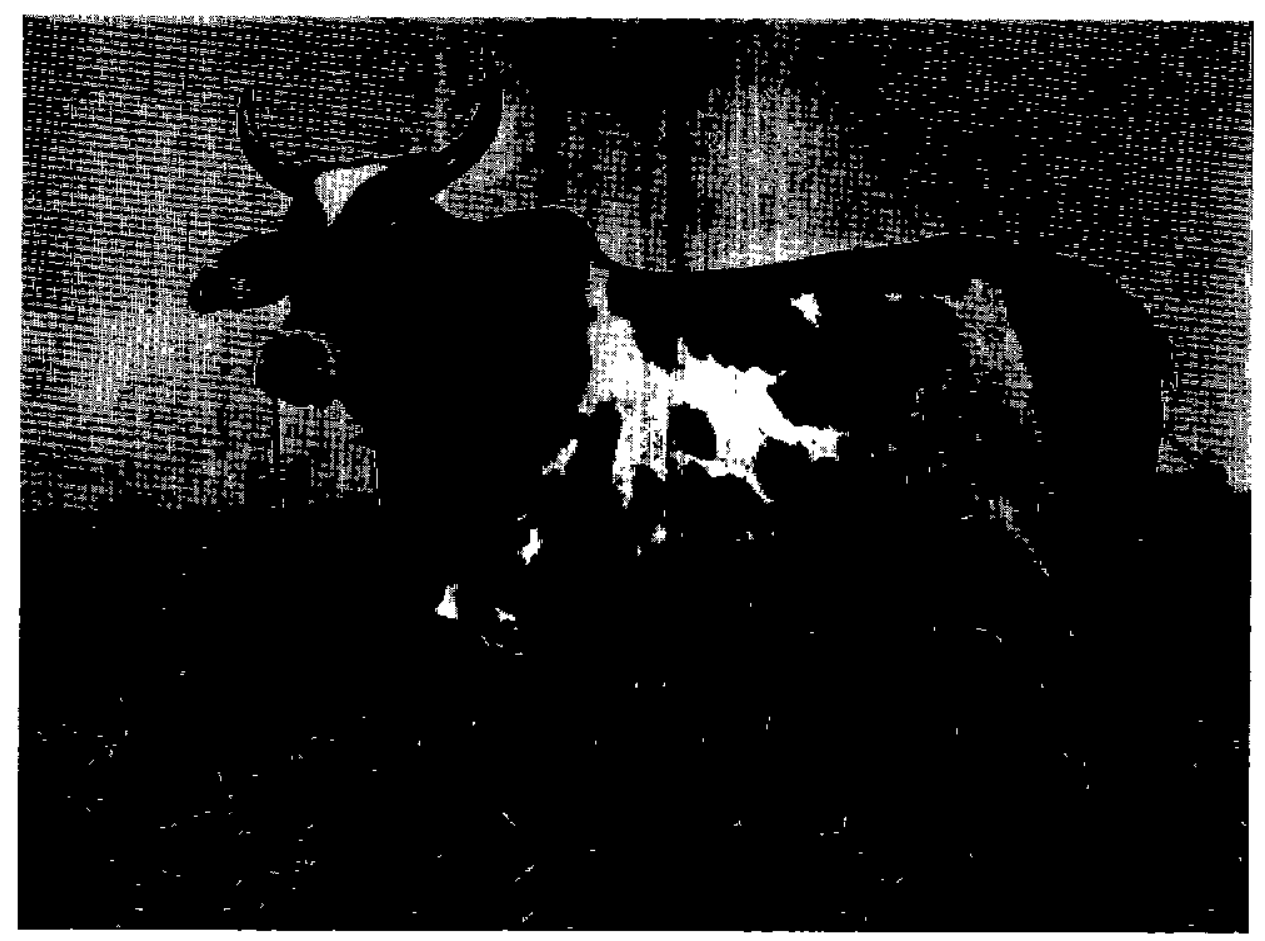

Cliché 4 : Femelle demı-Brahman (4 ans). 


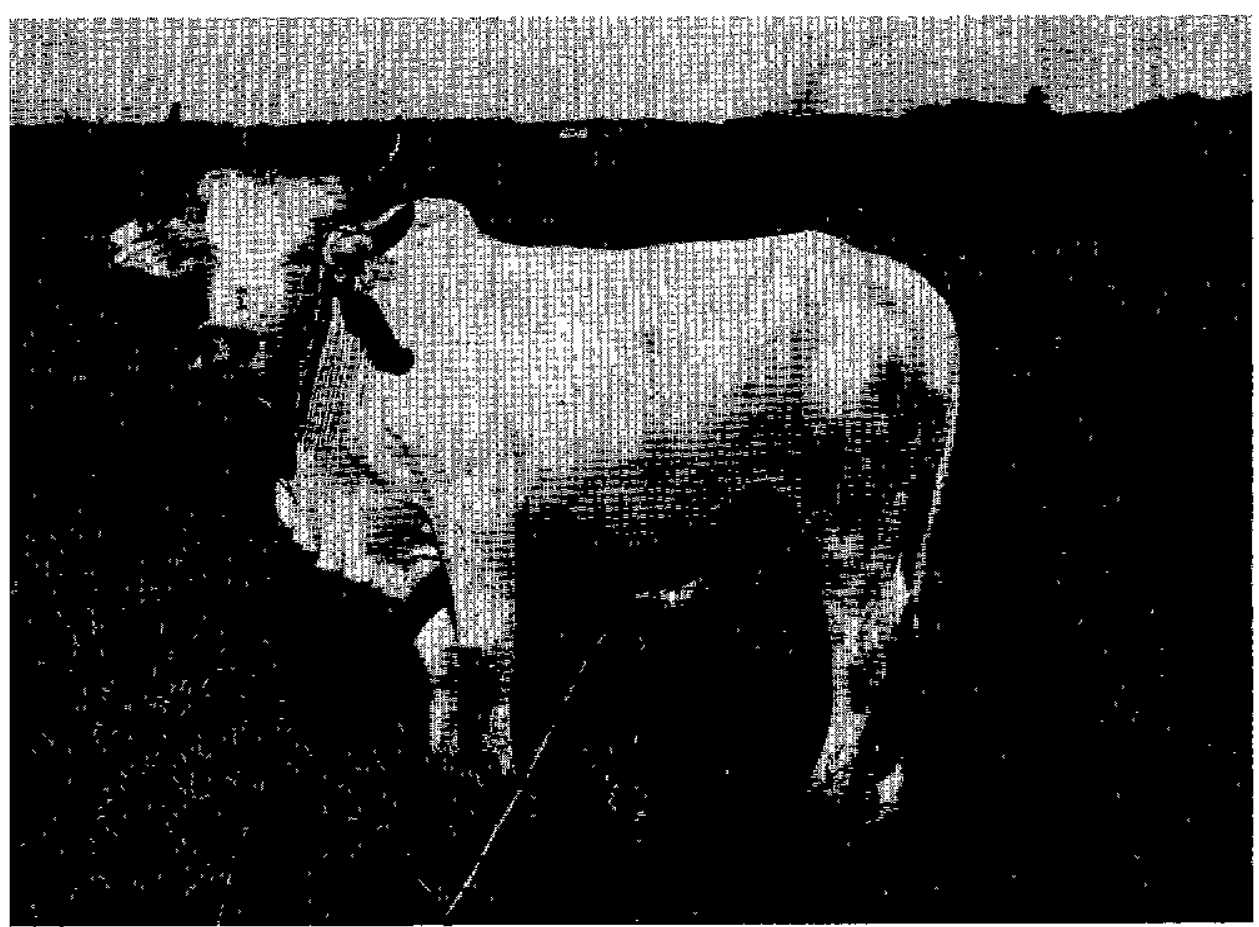

Cliché 5 : Mâle $3 / 4$ Brahman (4 ans).

Le croisement Brahman améliore nettement le format dès la première génération, les caractères extérieurs de la race Brahman s'affirment en deuxième génération (țête, robe).

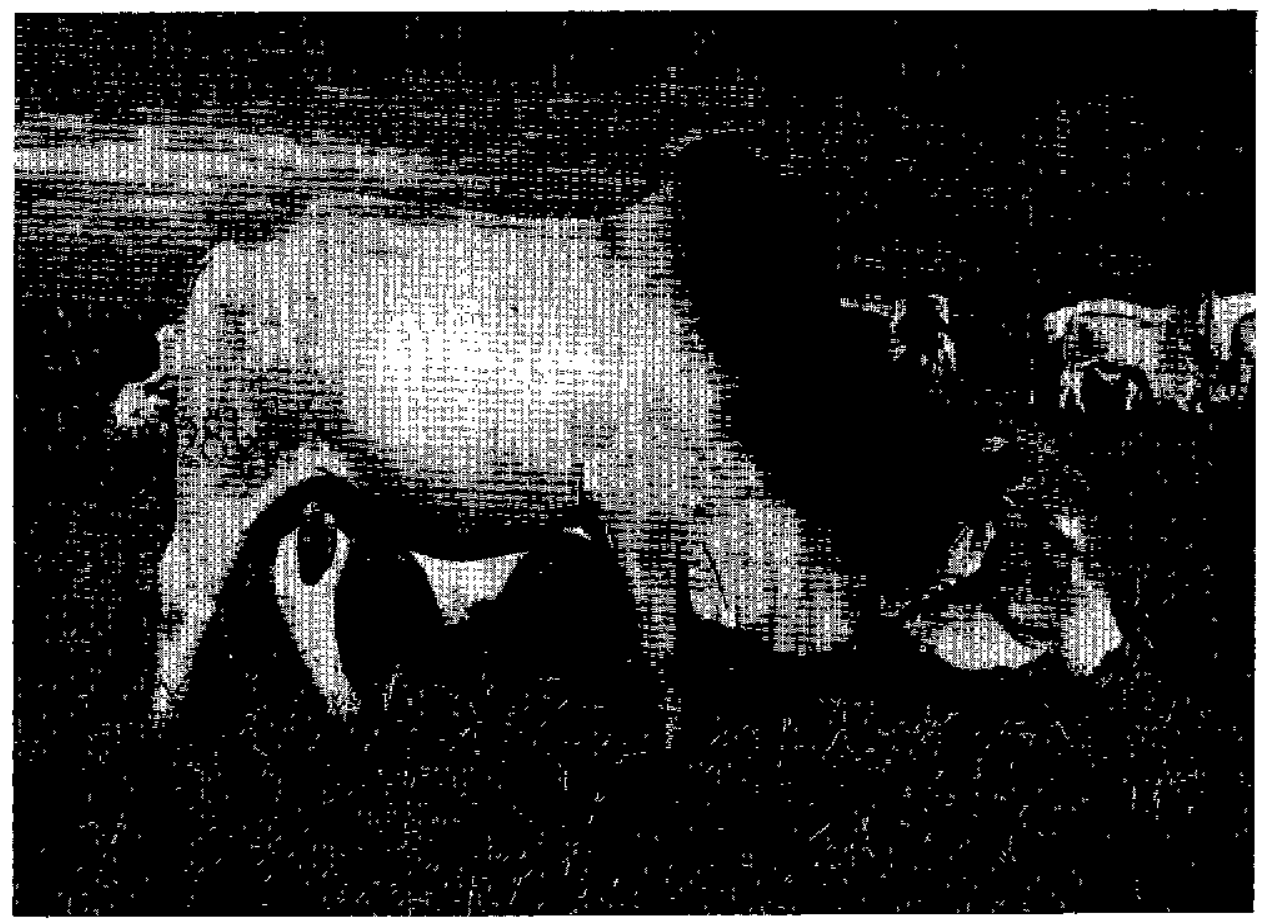

Cliché 6 : Taureau Brahman né et élevé à Madagascar. 


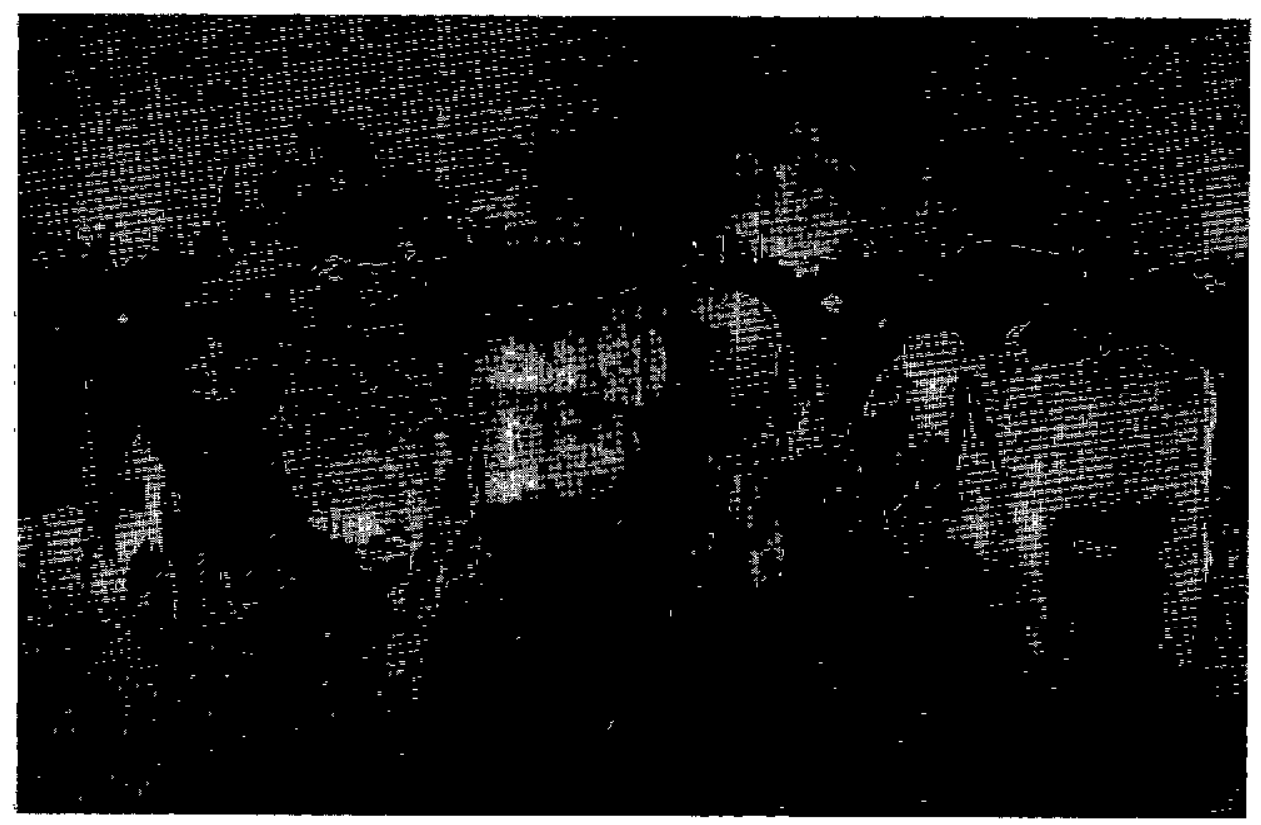

Cliché 7 : Vache Brahman née à Madagascar et son veau.

Les animaux de race Brahman paraıssent s'adapter très convenablement au climat des régions chaudes de Madagascar. 


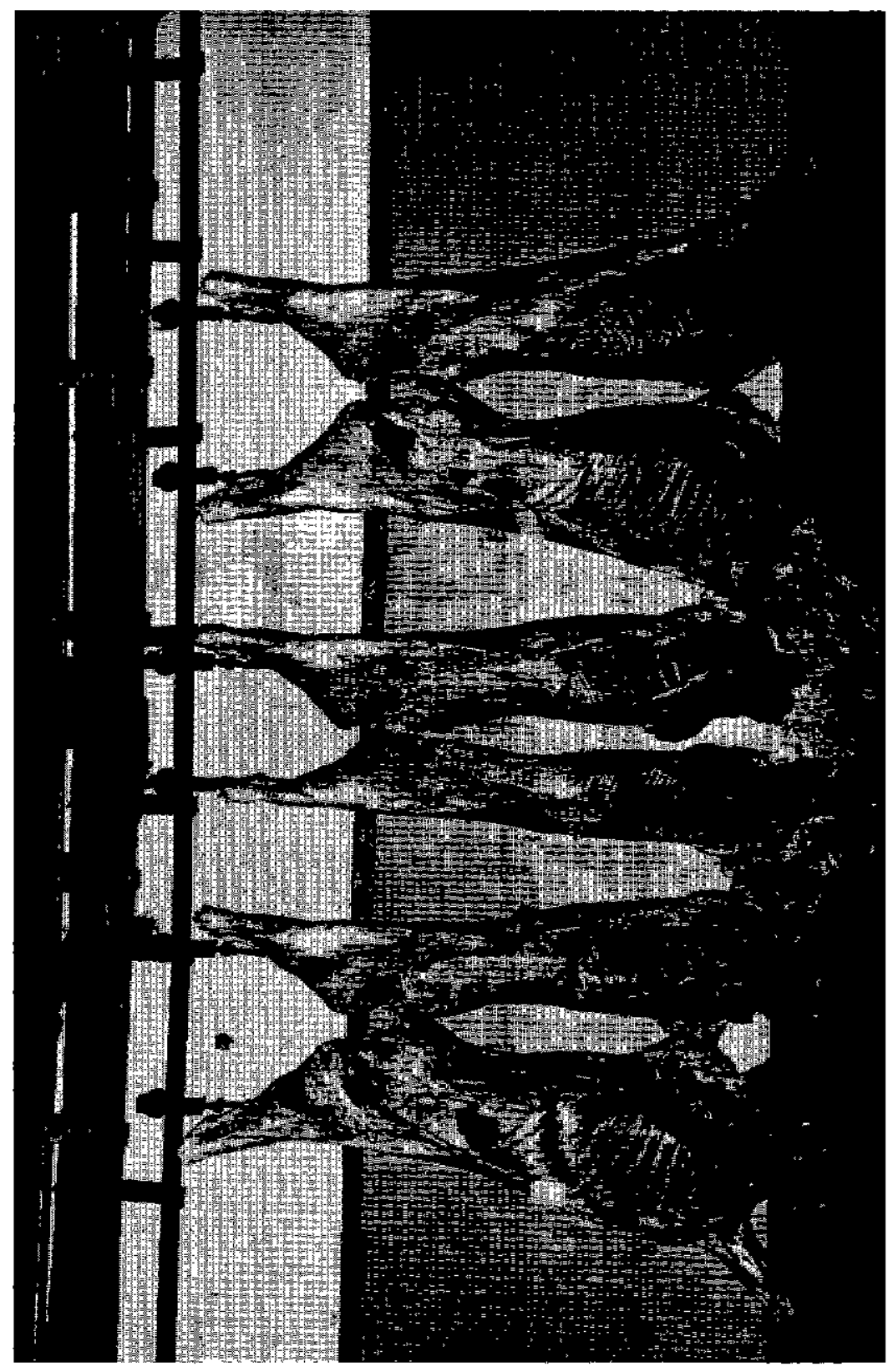

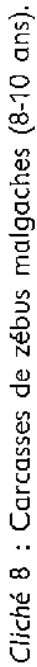




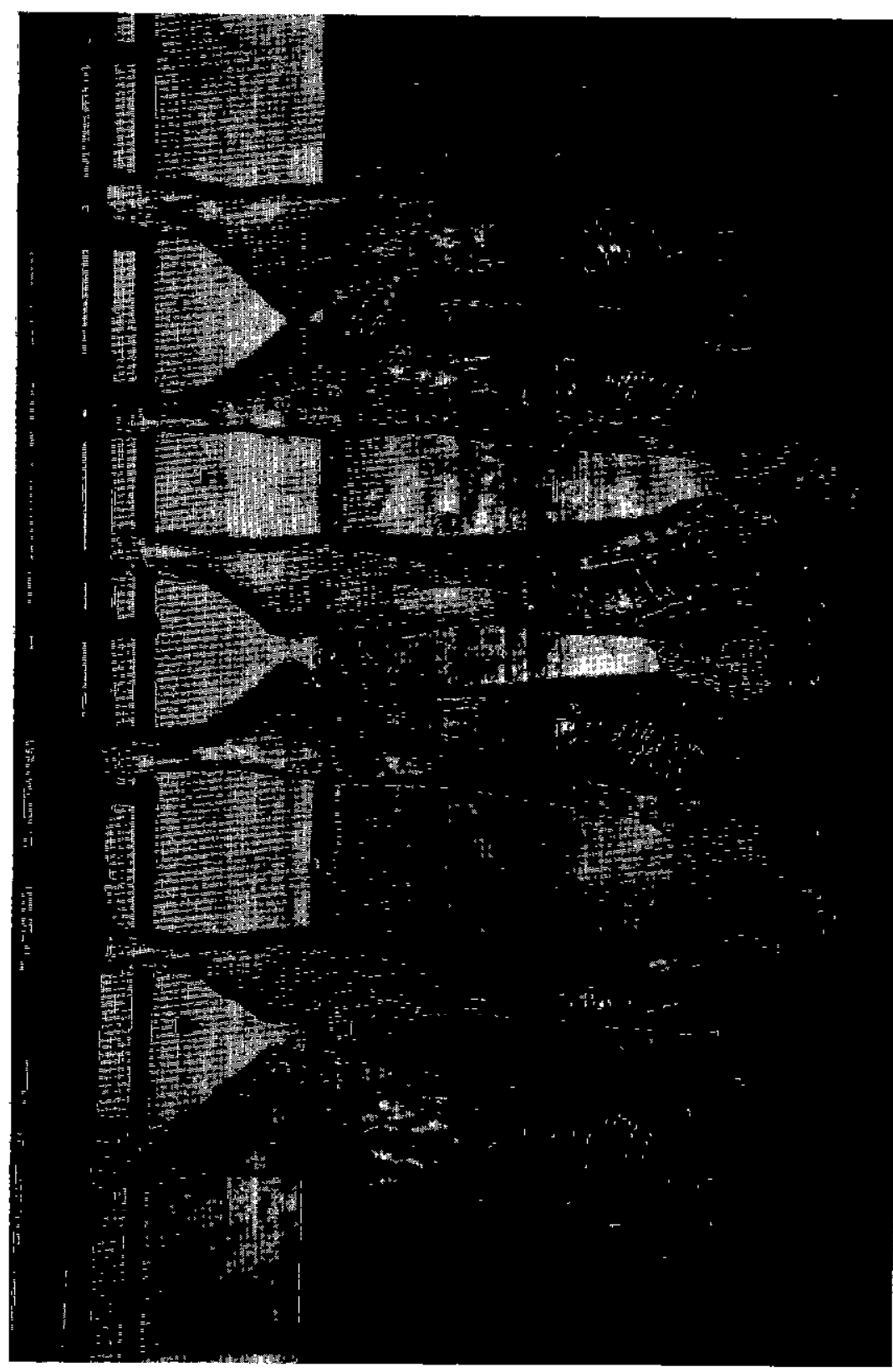

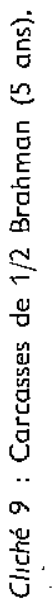




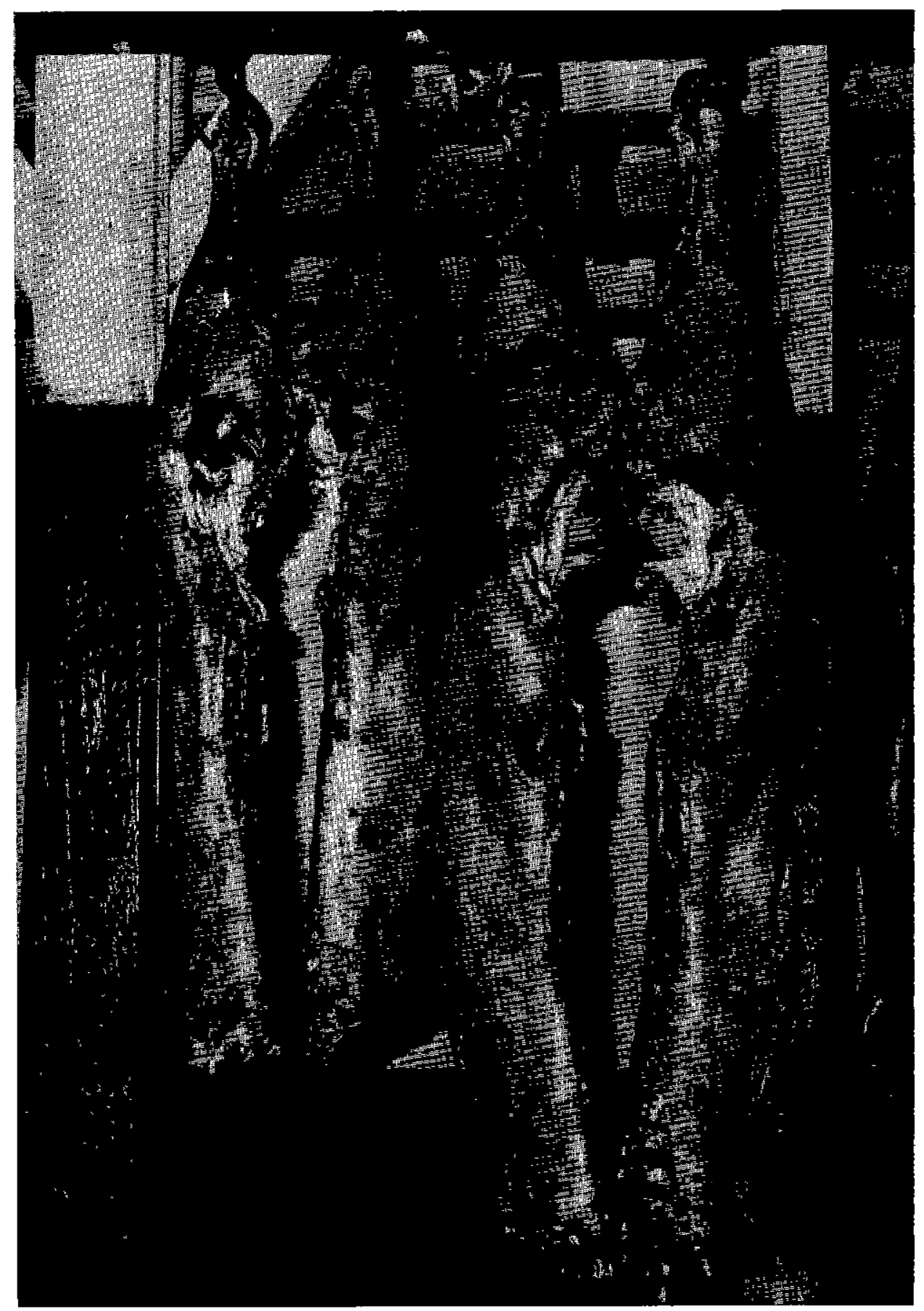

Cliché 10: Pans de zébu malgache et de $3 / 4$ Brahman au même âge ( 5 ans).

On note une augmentation consıdérable du format, ainsi qu'une amélıoration du rapport arrière/avant. 


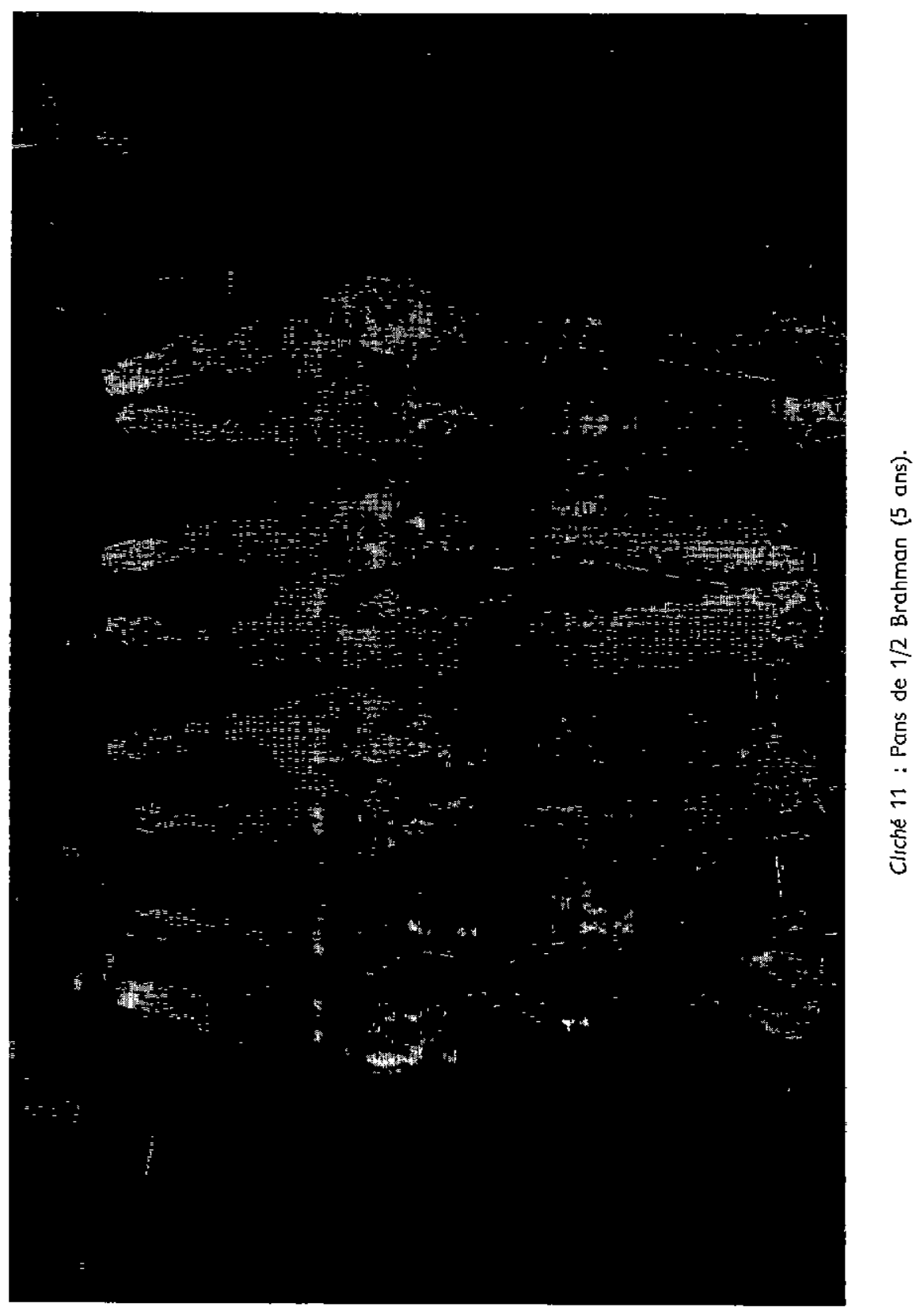




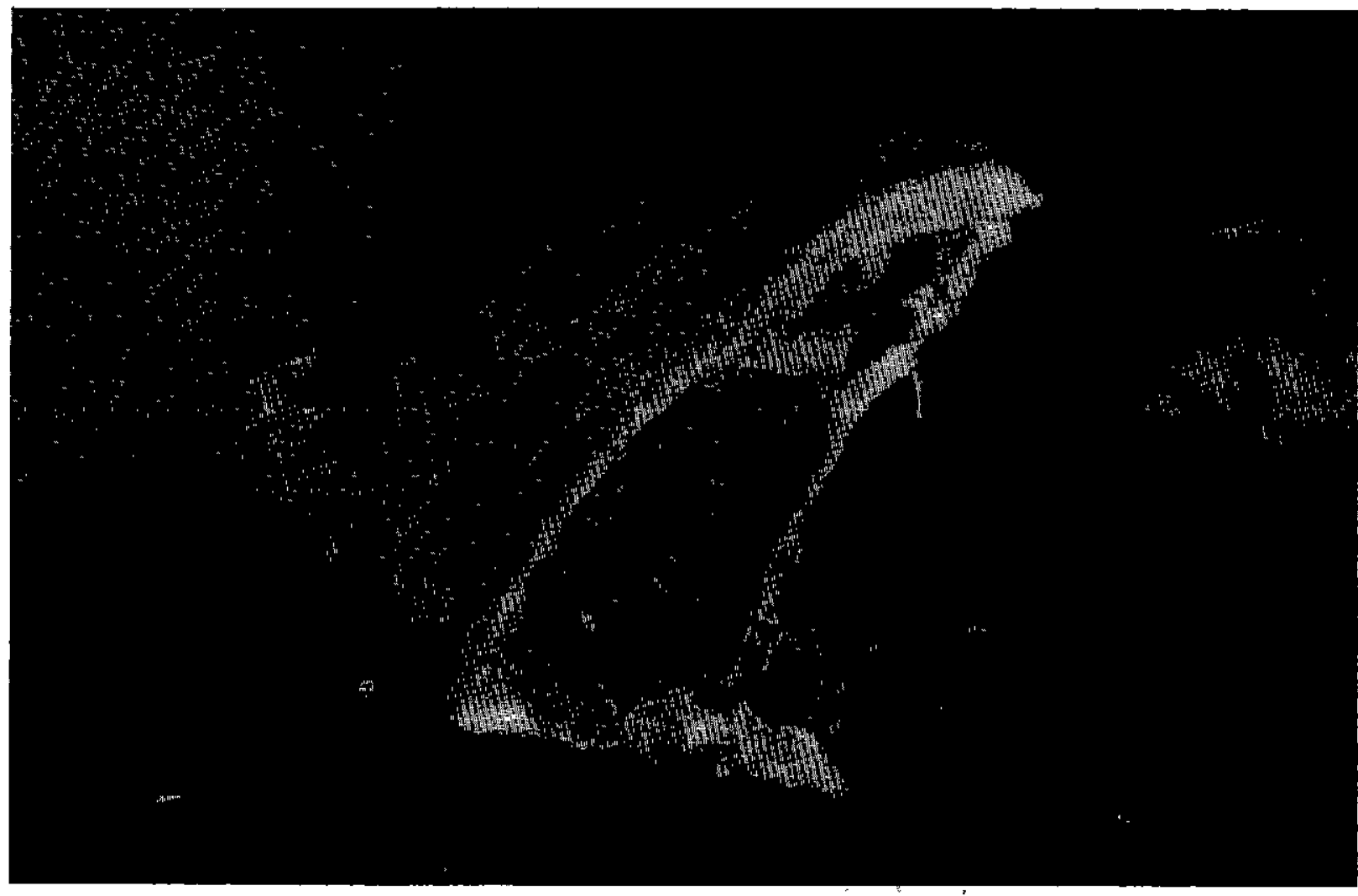

Cliché 12: Coupe du train de côtes d'un demi-Brahman.

La proportion gras/muscle est plus correcte sur le demi-Brahman que sur le zébu malgache qui a־tendance à devenir trop gras si on le nourrit bien, 


\section{EXTRAITS - ANALYSES}

\section{Maladies à virus}

69-131 SERRES (H.) et RAMISSE (J.). - Introduction de la peste porcine à Madagascar. Rev. Elev. Méd. véf. Poys trop., 1969, 22 (3) : 315-18.

La peste porcıne a été ıntroduite à Madagoscar une première fois en 1965 et sans doute une deuxième fois en 1967. Le retard du diagnostic n'a pas permis l'éradication et la peste porcine doif être consıdérée comme ımplantée dans le pays. Le développement des échanges, partıculıèrement aérıens, diminue considérablement l'abrı ınsulaire contre les épizoolies.

69-132 RAMISSE (J.), SERRES (H.), RAKOTONDRAMARY (E.), - Isolement à Madagascar de virus associés à la dermatose nodulaire bovine. Rev. Elev. Méd. vét. Pays trop., 1969, 22 (3) : 357-62.

Les aureurs ont isolé sur celiules rénales de veau en culture, des virus provenant de nodules cutanés prélevés chez des bovins locaux (zébus ou métis). Les caractères cytopathogènes (lyse cellulaire et inclusion) de ces virus ont été comparés à ceux des souches Sud-Africaines associées d̀ la dermatose nodulaire. L'analogie de comportement entre les souches locales et NEETHLING, ainsi que les résultats sımilaıres de la séro-neutralisation nous font penser que ces souches sont Irès proches, sinon identiques.

69-133 RAMISSE (J.), SERRES (H.), RAKOTONDRAMARY (E.). - Adaptafion aux cellules rénales de lapin de virus associés à la dermatose nodulaire bovine. Rev. Elev. Méd. vét. Poys trop., 1969, 22 (3) : 363-71.

Les auteurs ont adapté les souches locales et NEETHLING, agents de la dermatose nodulare, aux cellules rénales de lapın Elles provoquent la destruction des cellules ef la formation d'inclusions cyloplasmiques. Après un certain nombre de passages les souches virales sont encore pathogènes pour le veau. La séro-neutralısation montre l'identité entre les souches locales et NEETHLING. Elles ne sont pos hémagglutinantes. Leur acıde nucléique est de l'ADN.

69-134 RIBEIRO (M.) et SUREAU (P.). - Vaccin anticlaveleux Iyophilisé à virus sensibilisé. Arch. Inst. Pasteur Algérie, 1967, 45 :11-29. (Résumé des outeurs).

Après un bref rappel de la découverte, il y a plus de cinquante ans, à l'Inshituł Pasteur d'Algérie par BRIDRE el BOQUET, de la vaccination anticlaveleuse par virus sensibilisé, les auteurs passent rapidement en revue les autres types de vaccin anticlaveleux mis au point et ufilisés plus récemment dans divers pays et les perfectionnements apportés à ces vaccıns (vaccıns adsorbés et vaccins lyophilısés).

Les auteurs décrivent ensuite la technique actuellement utilisée à l'Instıtut Pasteur d'Algérie pour la préparation du vaccın anticlaveleux à virus sensibilisé selon la méthode des mélanges tıtrés de BLANC et MARTIN el pour la lyophilisation de ce vaccin. Ils donnent, pour termıner, les résultats obtenus en ce qui concerne l'innacuité de ce vaccin sensibilisé lyophilisé, sa durée de conservation (qui dépasse sept mas à $+20 / 25^{\circ} \mathrm{C}$ et à $+4^{\circ} \mathrm{C}$ et deux moıs à $\left.+37 / 39^{\circ} \mathrm{C}\right)$ et la durée de l'ımmunité conférée qui est d'au moins un an.

69-135 SCHNEIDER (L. G.). - Le test de la cornée : une nouvelte méthode pour le diagnostic de la rage in vivo. (The cornea test : a new method for the intra-vitam diagnosıs of rabies). Zbl. Vet. Med., 1969, B, $16: 24-31$.

Dans cet article, on décrit une méthode pour le diagnostic précoce de la rage : on applique sur ta cornée des souris el des chiens des lames porte-objet, pour y faire adhérer des cellules épithéliales qui seront ensuite fixées et colorées selon la méthode 
d'immunofluorescence. Dans les cas positifs, 0.1 à 15 p. 100 des cellules examinées contiennent des amas d'antigène fluorescent, dans leur cytoplasme. Ce test a permis le diagnostic de la rage sur plus de 70 p. 100 des souris infectées expérimentalement avant que se manifestent les premiers symptômes. Il y a simultanéité de l'apparition du virus dans la cornée et dans les glandes salıvaires qui restent non infectieuses auss! longternps que le test de la cornée demeure négatıf.

69-136 PILO MORON (E.), VINCENT (J.), SUREAU (P.) et NEEL (R.). - Diagnostic rapide de la rage par l'inoculation du cerveau et de la glande sous-maxillaire aux souriceaux et par l'immunofluorescence. Arch. Inst. Pasteur Algérre, 1967, $45: 5-10$. (Résumé des auteurs)

Dans le diagnostic expérimental de la rage par inoculation aux animaux de laboratoıre, Il esł possıble de dımınuer très notablement les délais nécessares à l'obtention d'une réponse positive, en substituant les souriceaux aux sourıs adultes, en inoculant la suspension des glandes sous-maxillaires et en utilisant l'immunofluorescence directe systématıque d̀ compter du premier jour qui suit l'inoculation. II est cependant nécessaire d'opérer dans les mêmes conditions avec une suspension de cerveau, le virus pouvant être absent des glandes sous-maxillaıres. On peut ainsı obtenir une réponse positive en 4 à 5 jours avec le cerveau et en 3 à 4 jours avec les glandes sous-maxillaires.

Dans ces conditıons, if ne serait plus nécessaire d'attendre trois semaines pour écarter le diagnostic de rage, mais seulement, jusqu'à plus ample ınformé, une dizaıne de jours.

69-137 LePINe (P.), LeYADITI (J.), ATANASIU (P.), GUILLON (J.-C.) et GAMET (A.). - La vaccination du chien dans la lutfe contre la rage. Arch. Inst. Pasteur Algérie, 1968, 46 : 151-6. (Conclusion des auteurs)

Après avoır résumé les points acquis et cherché à mieux délimiter les points en discussion, Il paraît possible de formuler deux propositions :

1. dans la plupart des pays de l'Europe occidentale, en France notamment où la rage a pénétré, il serait inopportun de changer la législation existante, antérieure à la vaccination du chien, bien qu'elie ne prévole ni interdıse cette vaccination. Les risques de conflił prévisibles dans la période de transition nuiraient à la prophylaxie ;

2. Ceci étant admis, conformément à l'expérimentation et aux recommandations pressantes de I'OMS, de la FAO, de l'OIE, il reste hautement souhaitable que les organismes officiels chargés de la lutte antirabique des différents pays contaminés puissent utiliser l'arme si efficace qu'est la vaccination du chien.

Cette solution n'a rien d'original : c'est celle qu'en France a conseillée JACOTOT, qu'ont appliquée avec succès la Belgıque, I'Italıe, le Luxembourg et la Turquie. Cette attitude quasi générale est surtout celle du Canada qui applıque un programme de vaccination lorsque la fréquence de la rage dans une régıon le justifle et considère que «cette disposition ne dolt pas être prise en remplacement des mesures de prophylaxie concernant les chiens ».

69-138 GLEDEL (J.), MERED (B.) et SUREAU (P.). - Vaccins antirabiques inactivés par la bêta-propialactone préparés à partir de cerveaux de chevreau et de cerveaux de souriceau nouveau-né. Arch. Inst. Pasteur Algérie, 1968, 16 : 76-89. (Résumé des auteurs)

Dans le but d'élıminer toute virulence résiduelle de leur vaccin antırabıque, les auteurs ont préparé à partir de cerveau de chevreau des vaccins inactivés par la bêta-propiolactone. Après lyophilisation, ces vaccins se sont révélés avirulents pour la souris adulte. Ils possèdent un pouvoir vaccinant suffisant et celui-ci se maıntient même après une épreuve thermique à $+37^{\circ} \mathrm{C}$. Si ces résultats sont confirmés par de nouveaux essais, la production de ce type de vaccin sera à envisager.

Dans le but d'éliminer, partiellement, le risque que représente le facteur encéphalıtogène présent dans le tissu nerveux des anımaux adultes, les auteurs ont préparé, à partir de cerveau de souriceau nouveau-né, un vaccin inactivé par la bêta-propiolactone. Les résultats des contrôles d'activité sont favorables. La lyophilisation permet de conserver intact le pouvoir vaccinant pendant un an au moins. Néanmoins, pour des considérations d'ordre pratique, on ne peut envisager à l'heure actuelle de substituer ce vaccın au vaccin préparé à partir de cerveau de chevreau. 
69-139 PROVOST (A.), BORREDON (C.), MAURICE (Y.). - Identité immunologique de souches isolées en Afrique Centrale ef des souches Américano-Européennes du virus de la maladie des muqueuses. Ann. Inst. Pasteur, 1969, 117 (1) : 133-36. (Résumé des auteurs).

Des souches de virus de la maladie des muqueuses isolées en Afrique Centrale sont neutralisées par l'immunsérum correspondant à la souche de référence VD-NYI, et réciproquement, une souche d'origine allemande est neutralısée par les immunsérums correspondant aux souches africaınes.

\section{Peste bovine}

69-140 TAYLOR (W. P.). - Sensibilité du chameau à une basse (Cameius dromedarius) à l'infection par la peste bovine. (The susceptibility of the one-humped camel (Comelus dromedarius) to infection with rinderpest virus). Bull. eplzoot. Dis. Afr., 1968, 16 (4) : 405-10.

La souche virulente de peste bovine « Kabete $O$ » est ınoculée à un chameau réceptif par vole intraveineuse. Le sang prélevé sur l'anımal entre le $3^{\mathrm{e}}$ et le $8^{\mathrm{e}}$ jour ne provoque aucun effet cylopathogène en culture de cellules de rein de bovin; par contre inoculé à des bouvillons, il développe chez eux les réactions typiques provoquées par la souche Kabete $O$. Une réaction de séro-neutralisation montre la présence d'anticorps neutralisants au $14 \mathrm{e}$ jour. Ni le degré de virémı, ni sa durée totale, n'ont été définis. Lo souche virulente RGK/I provoque une virémie de faible degré qui dure six jours, chez un des deux chameaux ayant subi les inoculations sub-cutanées. Tous les deux acquièrent, cependant, des antıcorps neutralisants. La virémie a également été dépistée sur deux ou trois chameaux infectés par contact avec des excrétions de bétail. Si le taux des anticorps est à peu près comparable à celui relevé chez le bétail infecté, il n'en est pas de même du taux de virus dans le sang.

L'infection produife par les deux souches virulentes de peste bovine utilisées dans cette expérience a eu un caractère clinique fruste, exception fatte de la brève pyrexie remarquée au $6^{e}$ jour chez l'un des chameaux expérimentaux.

Il n'a pas été possible de transmettre le virus de chameaux infectés, solt à des bovins, soit à d'autres chameaux, bien que les chameaux puissent être contamınés par des bovins atteints.

On a donc conclu que les chameaux peuvent contracter des infections frustes par le virus de la peste bovıne mais qu'ils ne jouent probablement pas un rôle important dans l'épizootiologie de la maladie.

69-141 JOHNSON (R. H.), RITCHIE (J. S. D.). - Un virus associé à un syndrome de pseudo-peste bovine chez les chèvres naines de Nigeria. (A virus associated with pseudorinderpest in nigerian dwarf goats). Bull. epizoot. Dis. Afr., 1968, 16 (4) : 411-17.

Un virus à effet cytopathique comparable à celui décrit pour l'agent de la peste des petıts ruminants (PPR) a été isolé des muqueuses intestinales et des giandes lymphatiques de drainage chez des caprins nains nigériens qui présentaient un syndrome de pseudopeste comparable à la PPR. L'inoculation du matériel suspect à des cultures monocellulaires de première explantation de reins de chevreaux ou d'embryon bovin, conduit à l'apparition de petifes cellules multinucléées, s'élargissant progressivement jusqu'à atteindre la forme d'un cadran d'horloge avec une couronne de plus de 100 noyaux. De larges inclusions nucléaires, entourées d'un halo, se développent en nombre variable (de 1 à 6). Elles accupent plus des deux tiers du nucléoplasme. La chromatine normale reste à la lisière des halos ef de la membrane nucléaire, sans montrer de noircissement ou de condensation comme on a l'habilude de l'observer dans les inclusions de Cowdry type $A$. Le cytoplasme de la cellule, très éosınophile, contient également des inclusions allongées ou en triangle, entourées aussi d'un haio, ef de larges vacuoles.

La différence essentielle avec les virus bovipestıque et morbilleux réside en la présence d'inclusions intranucléares pour les systèmes cellulaires employés. Le virus n'a jamais pu être isolé des prélèvements de rate, de foie ou de rein.

Après leur guérison quelques animaux onl présenté des croûtes à la lèvre. L'inoculation d'une émulsion de ces croûtes à des cultures cellulaıres n'a donné aucun effer cytopathique malgré plusieurs passages et la microscopie électronique r'a décelé aucun virus du groupe variole.

Irrégulıèrement un agent ressemblant à Dermatophilus congolensis a été isolé. 


\section{Maladies bactériennes}

69-142 SAGNA (F.). - Salmonellose de la poule à « Salmonella pikine ». Rev. Elev. Méd. vét. Pays trop., 1969, 22 (3) : 335-36.

Sallmonela pikine a été isolée pour la première fois à Dakar par S. et L. LE MINOR, $P$. KIRSCHE, R. BAYLET et J. SAMAILLE en 1958 d̀ partir d'un ganglıon mésentérıque de porc apparemment normal.

Cette souche est de nouveau isolée en mars 1968, à Dakar, au Laboratoire national de l'Elevage el de Recherches vétérinaires, à partir de poulets malades provenant d'un élevage familial de la zone suburbaine de Dakar. Le pouvoir pathogène de ce sérotype vis-à-vis des volailles est ainsi confirmé.

69-143 LE MINOR (L.), CHAMOISEAU (G.), BARBE (E.) et collab. - Dix nouveaux sérotypes de Salmonella isolés au Tchad. Ann. Inst. Pasteur, 1969, 116 (6) : 775-80. (Résumé des auteurs).

Description de 10 nouvecux sérotypes du sous-genre I et de deux variantes diphasiques de sérotypes décrits antérieurement comme monophasiques : $S$. bongor $\left(48: Z_{35}:-\right)$, S. bousso $\left(1,6,14,25: z_{4}, z_{23}:-\right)$, S. echa $(38: k: 1,2)$, S. gossi $\left(35: e, h: z_{6}\right)$, S. gor $(17: z: 1,2)$, S. higco $(30: 1, v: 1,2)$, S. logone $(39: d: 1,5)$, S. madiago $(1,3,19: c: 1,7)$, S. rogy $\left(28: z_{10}: 1,2\right)$, $S$. toucra $\left(48: z: 1,5:\left(z_{58}\right)\right)$, $S$. bousso var. diphasique $\left(1,6,14,25 ; z_{4}, z_{31}: e, n, z_{15}\right), S$. saro var. diphasique $\left(1,6,14,25: z_{3 g} ; e, n, x\right)$.

69-144 CERRUTI (C. G.) et collab. - Emploi d'un vaccin d'ovoculture contre I'infection pasteurellique des buffles. Att Soc. ital. Sci. vet., 1967, 21 : $827-30$.

Ce vaccin d'ovoculture est inoffensif pour la souris, le lapin, le cobaye ef le buffle : il est préparé sur embryon de poulet, inactıvé par le formol à 0,25 p. 100 et additionné d'un adjuvant de type huileux.

Sur 17 buffles vaccinés, 16 résistèrent aux différentes épreuves par une souche virulente de Posteurella, effectuées 60 jours après la vaccination et à intervalle régulıer de 30 jours jusqu'à 360 jours ; seul le buffle éprouvé à 210 jours mourut de l'épreuve

Un titre notable en anticorps fut décelé par le moyen de l'hémagglutinatıon passive, dans les semaines qui suivirent la vaccination.

Employé dans un foyer naturel de Pasteurellose, ce vaccin provoqua l'élaboration d'anticorps en quantité notable et décelables encore après $6 \mathrm{mo}$ is; il se révéla ınoffensif pour les femelles gestantes près du terme et conféra aux animaux une bonne protection tandis qu'on pouvalt observer 20 à 30 p. 100 de mortalité chez les buffles non vaccinés.

69-145 GIDEL (R.), ALBERT (J. P.), RETIF (M.). - Enquête sur la fuberculose bovine au moyen de fests tuberculiniques dans diverses régions d'Afrique Occidentale (Haute-Volta et Côte-d'Ivoíre). Résultałs ef considérations générales. Rev. Elev. Méd. vét. Pays trop. 1969, 22 (3) : $337-55$.

En 1967 et 1968, les Sous-Sections Tuberculose el Zoonoses du Centre Muraz à Bobo-Dioulasso, ont effectué 5 enquêfes couplées sur l'épidémiologie de la fuberculose humaine et de la tuberculose bovine en Afrıque de l'Ouest. Ces enquêtes ont été effectuées au moyen de tests tuberculinıques ef par sondage aléatoire dans diverses zones clımatiques de Haute-Volra et de Côte-d'lvoıre, allanł du quinzième degré de latitude Nord (zone sahélıenne) au quatrıème degré de latıtude Nord (zone côtıère).

Les auteurs exposent ici les résultats de ces enquêtes pour ce qui concerne la tuberculose bovine. 8.132 bovins ont été tuberculınés au total ; chaque animal a été l'objet d'une double tuberculination effecłuée simultanément en deux régions différentes à l'alde de tuberculıne humano-bovine et tuberculıne aviaire.

II ressort de l'analyse statistique des résultats que des différences significatives sont observées d'une part entre les régions prospectées et d'autre part, dans une même région, selon l'âge des anımaux tuberculinés. Enfin, l'étude comparatıve des résultats des enquêtes humaines et animales en région sahélienne montre l'incidence de la tuberculose bovine sur la population humaine de ces régions, en particulier chez les jeunes enfants. 
69-146 HART (C. B.) ef TYSZKIEWICZ (K.). - Dermatite mycotique chez le mouton. III. Chimiothérapie avec le sulfate double de potassium ef d'aluminium. (Mycotic dermahtis in sheep. III. Chemotherapy with potassium aluminium sulphate). Vet. Rec., 1968, 82 (10) : 272-81.

L'application d'une solution à 1 p. 100 de sulfate double d'aluminium et de potassium (alun) en bain a un effet bénéfique contre l'infection arhficielle du mouton par Dermatophilus congolensis : cet effet est plus prononcé et plus prolongé que celui du sulfate de cuivre à 0,2 p. 100 ou du 2-4-5-trichlorophénol d̀ 0,1 p. 100 Dans un test semblable, le butyl 2-4-dichlorophenoxyacétale à 0,128 p. 100 montre une efficacité limitée de durée relativement courte et quand, par la suife, ce composé fut testé de façon plus étendue contre la maladie nafurelle, son effet limité fut presque toujours dépassé. L'alun a donc été expérımenté sur une écheile plus large contre la maladıe naturelle. Dans chacune des cınq expériences comprenant seulement un bain, il y eut une amélioration significative à un ou plusieurs examens après le commencement de l'expérımentation. Dans huit autres expériences, le fraitement comprenait une friction avec de l'alun à 1 p. 100 ou un poudrage avec de l'alun anhydre à 57 p. 100 dans une matière inerte, avec ou sans bain préalable. Une amélıoration, hautement ou très hautement significative par rapporl aux témoins, a été relevée dans chaque expérımentation.

Les emplois de l'alun et leurs limites pour la lutte et le traitement de la dermatite mycotique sont discutés et un programme pour le trastement de routine est tracé : des modifications possıbles qui pourraient être plus économıques sont mentionnées.

\section{Mycoplasmoses}

69-147 PROVOST (A.). - Recherches immunologiques sur la péripneumonie. XI. Conception immuno-pathogénique de la maladie. Rev. Elev. Méd. vét. Pays trop., 1969, 22 (3) : 319-34.

Une thèse est présentée selon laquelle l'alteinte lésionnelle primitive de la péripneumonie bovine est lymphatique et est consécutive à la création d'un phénomène d'ARTHUS intraganglionnare dans les ganglions lymphatiques drainant le poumons. L'hypothèse s'accorde parfaitement avec les faiłs anatomiques, immunologiques, cliniques, anatomo-pathologıques ef épızootiologıques de connaissance classique dans la péripneumonie et est soutenue par deux résultals expérımentaux.

69-148 StONe (S. S.), MASigA (W. N.), ReAD (W. C. S.). - Passage transplacentaire de $M$. mycoides chez les bovins. (Mycoplasma mycoides transplacental transfer in cattle). Res. Vet. SCi., 1969, 10 (4) : 368-72.

Six vaches sont infectées artıficiellement par $M$. mycoides, par la voie endabronchique, 2 à 4 semaines avant leur terme. Les mères et les veaux sont abattus dans les 6 heures qui suivent la parturition; les veaux n'ont pas absorbé de colostrum.

Le sérum des mères contient des anticorps fixant le complément et pour cing d'entre elles, on isole $M$. mycoides de la plupart des tissus ; on l'isole aussi chez quatre veaux nés de mères qui avaient des lésions pulmonarres très étendues.

Cef isolement de $M$. mycoides est confirmé par le test d'inhibition de crosssance et l'immunofluorescence.

Les ısolements sont négatifs à partir des tissus des veaux nés de mères dont les lésıons pulmonaires étaient peu importantes ou cicatrisées.

69-149 RAZIN (S.). - Taxonomie de Mycoplosma étudiée par électrophorèse des protéines cellulaires. (Mycoplasmo toxonomy studied by electrophoresis of cell proteins). J. Bact., 1968, 96 (3) : 687-94.

Les courbes électrophorétiques des protéınes cellularres sonł utilisées pour l'étude de divers problèmes taxonomiques dans l'ordre des Mycoplasmatales. Les courbes de 5 souches de Mycoplasma hominis montrent des différences nettes qui correspondent avec l'hétérogénéité connue de leur sérologie et de leur acide nucléique. Les courbes de troıs souches $M$. mycoìdes var. mycoídes, isolées en difiérenies régıons, sont essentiellement identiques. Les courbes électrophoréfiques de plusieurs souches caprınes ressemblent à celles de $M$. mycoìdes var, mycoìdes ce qui corrobore leur classification comme $M$. mycoides var. capri. 
Une souche $B_{\mathrm{g}}$, isolée du porc, est expérimentalement identifiée comme $M$. mycoides var. capri. La souche de la mammite bovine $M$. agalactıe var. bovis possède une courbe fondamentalement semblable à celle de la souche de la mammite caprine $M$. agaloctioe, ce qui incite à grouper les 2 souches dans une même espèce.

Trois souches $M$. pulmonis isolées de rats ou de cultures de tissus montrent des courbes très proches. La courbe de la souche toxigène $M$. neurolyticum (Sabin $A$ ) ressemble mais n'est pas identique, à celle de la souche non toxigène $P G_{28}$. Les Mycoplosmas aviaires, $M$. gollisepticum et $M$. iners, présentent des courbes spécifiques et faciles à distınguer, ce qui est en accord avec leur classıfication actuelle en dıfférentes espèces. Plusieurs améliorations dans la technique électrophoréíque sonf décrites et ses avantages et ses limites en tant qu'ınstrument taxonomique sont discutés.

69-150 MASIGA (W. N.), STONE (S. S.). - Immunofluorescence et précipito-diffusion en gélose pour défecter $M$. Mycoídes dans les lésions pulmonaires fraîches et fixées par le formol des bovins péripneumoniques. (Fiuorescent antibody and agar gel diffusion techniques to detect Mycoplasma mycoides in fresh and formalin-fixed lung lesions of cattle). Bull. epizoot. Dis. Afr., 1968, 16 (4) : 399-404.

La méthode des anticorps fluorescents applıquée à la recherche de M. Mycoides dans les lésions pulmonaires des bovins pérıpneumoniques permet :

1. De déceler le germe, même en phase filamenteuse, dans les lésions aiguës ou chronıques.

2. D'utiliser des prélèvements fixés par le formol, ayant jusqu'à 50 jours de fixation.

Le test de précipito-diffusion en milieu gélifié permet de déceler les antigènes spécifiques dans ces mêmes prélèvements après 28 jours de fixatıon et, comme l'on pouvait s'y attendre, l'antıgène principal mis en évidence est le galactane.

69-151 AL-AUBAIDI (J. M.), FABRICANT (J.). - Techniques d'isolement des mycoplasmes des bovins. (Technics for the isolation of Mycoptasma from cattle). Cornell vet., 1968, $58: 555-71$.

Les auteurs utilısent 8 milieux différents pour isoler les mycoplasmes à partir de prélèvements effectués sur 311 vaches et taureaux, en employant trois méthodes principales : isolement dırect sur milıeu gélosé, isolement en milieu liquide, isolement en milieu diphasıque.

Aucune méthode et aucun milieu ne permit l'isolement de la totalité des souches ; mais un milieu de base composé de PPLO Broth Difco, d'extrait de levure, d'acide desoxyribonuclérque de sérum de cheval et de tampon au phosphate de potassium, se révéla très satisfaisant pour les mycoplasmes existant dans le laut.

II semble nécessare de disposer de plusieurs milieux pour les isolements primaires ; la fréquence de ceux-ci est toujours augmentée par les apports de facteurs de croissance.

\section{Maladies diverses à protozoaires}

69-152 PIPANO (E.). - Immunisation de bovins contre I'infection à Babesiella berbera. I. Infection de bovins avec le sang de porteurs évidents et latents. (Immunization of cattle against Babesiella berbera infection. 1. Infection of cattle with blood from patent and latent carriers). Refuah Vet., 1969, 26 (1) : 11-18. (Traduction du résumé de l'auteur).

Au cours d'essais de laboratoire, des veaux et des bovins adultes ont été inoculés avec du sang de porteurs chroniques latents ou évidents de Babesiella berbera.

La réponse des animaux inoculés avec du matériel identıque variait considérablement en durée et en intensité.

II n'y avait pas de différence dans la gravité de la réaction entre les animaux inoculés de sang à parasıtes visibles dans les étalements et ceux inoculés avec du sang de porteurs latents.

Les veaux ont montré des réactions faıbles à graves et se sont rétablıs sans nécessiter de traitement. Les adultes ont montré des réactions allant de faibles à très graves. Cinq d'entre eux ont dô être soumis à un tratement et deux sont morts.

Les facteurs impliqués dans la réponse des bovins à l'inoculation avec Babesiella berbera font l'objet d'une discussion finale. 
69-153 WINTER (H.). - Numération directe des profozoaires du sang par la microscopie ì fluorescence. (Direct counting of protozoa of blood by fluorescence microscopy). Am. J vet Res., 1968, 29 (12) : 2419-22. (Traduction du résumé de l'auteur).

La numération directe de Babesia bigemina et Babesıa argentına par la microscopie ̀̀ fluorescence, dans une chambre de numération conçue spécialement, est moins longue et plus précise que la méthode indirecte courante de numération par rapport aux érythrocytes dans des frottis colorés au giemsa. Les principaux avantages sont :

- la suppression des numérations d'érythrocyłes dans les frothıs et des numérations totales d'érythrocytes ;

- une préparation très sımple des prétèvernents ;

- une fluorescence d'un rouge brillant avec un noyau jaune en contraste qui rend les organismes, y compris les parasites endommagés qui n'auraient pu être identifiés autrement avec cerhitude, très apparents sur un fond noir.

Les organismes sont vus distinctement à fort grossıssement à sec, et de cette façon, de plus grandes surfaces peuvent être examinées dans un temps plus court que celui nécessaire à l'examen de frottis colorés au giemsa avec un objectif à immersıon.

L'attention a été attirée par la disparition des Babesia dans les prélèvements de sang recueillis quelques jours plus tôt. En 7 jours, te nombre des organismes reconnus par la mıcroscopie à fluorescence c été réduit de près de $250.000 / \mathrm{cmm}$ à moins de $14.000 / \mathrm{cmm}$. Une diminution semblable a été trouvée pour les hématozoaires complés par la méthode indirecte.

\section{Parasitologie}

69-154 DAYNES (M.). - La Distomatose à Madagascar. L'utilisation des molluscicides dans la lutte contre Lymnea natalensis hovarum (hâte intermédiaire de Fasciala gigantica). Rev. Elev. Méd. vét. Pays trop., 1969, 22 (3) : 385-92.

L'auteur relate 3 expériences d'utilisation de molluscicıdes dans les conditions écologıques du Moyen Ouest de Madagascar pour lutter cantre Lymneo natalensis hovorum. Compte tenu des difficultés d'ulılisation dues à l'écologie, il conclut que cette méthode de lutte contre la fasciolose apparaît alors comme non éconamique.

69-155 BOUCHET (A.), GRABER (M.), FINELLE (P.), DESROTOUA (J.) et GRENGDABO (A.). - Lo parasitisme du zébu dans l'Ouest de la République Centrafricaine. I. Parasitisme des veaux de lait. Rev. Elev. Méd. vét. Poys trop., 1969, 22 (3) : 373-83.

Dans l'Ouest de la République Centrafricaine, les auteurs signalent l'existence, chez les veaux de lait de 0 à 7 mois, de nombreux parasites, seuls ou associés entre eux, appartenant aux espèces suivantes : Neooscaris vifulorum, Strongylordes papillosus, Oesophagostomum (Bosicola) radiatum, Bunostomum phlebotomum. Cooperio punctata ef Cooperia pectinata, Haemoncus contortus et diverses Coccidies.

Les animaux sont atteints dans la proportion de 76,4 p. 100. Les laux d'infestation et la nature du parasitısme varient en fonction de l'âge et de la saison. La mortalité oscille entre 1 et 20 p. 100 , selon les troupeaux et les années.

II s'agit là, pour l'Elevage de la Républıque Centrafricaıne, d'un problème majeur, à résoudre d'urgence.

69-156 BIRGI (E.) et GRABER (M.). - Mollusques pulmonés d'eau douce basommatophores, vecleurs au Tchad d'affections parasitaires du bétail. Possibilités d'élevage au laboratoire. Rev Elev. Méd. vét. Pays trop., 1969, 22 (3) : 393-408.

Les auteurs, après avoır souligné l'ımporlance pour le bétail adulte des zones sahélosoudaniennes du Tchad dæs affectıons parasitares dues à certains Trématodes hépailques, stomacoux et veineux (Fasciala, Paramphistomum, Cormyerius et Schistosomes), décrivent une méthode simple et pratique permettant, dans des conditions climatiques très dures, l'élevage des principaux mollusques vecteurs.

Ils donnent également quelques indications concernant le cycle saisonnier de B. forskoli, $k$. jousseaumei, B. truncatus, $L$. natalensis, el s'efforcent de tirer les conciusions 
pratiques de cette étude, notamment en ce qui concerne la lutte contre ces mollusques ef l'époque la plus favorable pour traiter les animaux porteurs de Fosciola gigontica.

69-157 GRETILLAT (S.), VASSILIADES (G.). - Remarques concernant l'infestation expérimentale du cobaye par la souche ovest-africaine de Trichinella spiralis. C. R. Acad Scl., 1969, 268 D (11) : 1511-17. (Résumé des auteurs).

Chez le cobaye, une « barrière musculaire » ralentit l'enkystement normal des formes larvaires de la souche ovest-africaine de $T$ spiralis sans toutefois entraver leur développement biologique normal. Les examens trichınoscopıques faits de 35 à 100 jours après l'infestation révèlent la présence de très nombreuses larves libres voisinant avec des formes larvaires normalement enkystées et des kystes en voie de calcification.

\section{Entomologie}

69-158 UILENBERG (G.), HOOGSTRAAL (H.). - Ixodes randrianasolo sp. n. (Ixodoidea, Ixodidae) parasite de Rattus rattus (Rodentia) à Madagascar. Ann. Parasit., 1969, 44 (1) : 93-96. (Résumé des auteurs).

Ixades randrianasoloi sp. n. est décrite d'après une fermelle récoltée à Madagascar sur Rattus ratfus. L'espèce se distıngue nettement des six autres Ixodes connues dans le pays, en particulier par la forme des auriculae.

69-159 UILENBERG (G.), HOOGSTRAAL (H.). - Ixodes nesomys sp. $n$. (Ixodoidea, Ixodjdae) parasite d'un rongeur malgache. Ann. Parasit., 1969, 44 (1) : 97-100. (Résumé des auteurs).

Ixodes nesomys sp. $n$. est décrite d'après deux femelles récoltées sur Nesomys sp. à Madagascar. L'espèce se rapproche de deux autres lxodes malgaches, 1. colasbelcouri Arthur et 1 . albignaci Uilenberg et Hoogstraal.

69-160 FORD (J.). - Exemple fourni par les tsé-tsé d'une restriction des populations par la limitation de la distribution de l'habitat. (The control of populations through limitation of habitat distribution as exemplified by tsetse flies). Symp. R. ent. Soc. London, $n^{\circ} 4$. Insect abundance. Ed. : TRE Southwood, 1968, Pp. 109-118.

L'abondance globale de toute espèce est lımitée non seulement par le degré de densité de sa population mais par les dimensions de son milıeu. Cet article traite des facteurs qui empêchent les tsé-tsé de s'éloigner des régions où on les trouve.

Les populatıons d'espèces du groupe morsitans sont lımitées en Afrıque du Nord ef du Sud des tropıques par des facteurs qui donnent nasssance à des corrélations avec des zones climatıques. Comme les lımites des zones à mouches avoısinent plus ou moins étraitement les climats aù les insectes sont incapables de survie, la tsé-tsé est de plus en plus sujetle à l'action de facteurs de lımıtation subséquente puisque la capacıté de l'habitat à pourvoir à tous les processus éthologiques nécessaıres à la vie se restreint de plus en plus.

Quand les limites sont liées géographiquement aux rives de l'océan ou d'un lac, le mécanisme de leur pouvoir d'arrêt est subordonné à la capacité du vol répondant à un stimulus visuel, par un processus identıque à celui qui empêche les populations de l'intérieur des ferres de se disperser à partir de la végétation arborée dans les prairies sans arbre à moins de trouver des moyens de transport disponibles. Certaines limites à l'intérieur des terres peuvent s'établir du falt de l'impossibulité de crolsements interspécifiques.

A l'intérieur des zones à mouches, qui peuvent comprendre une gamme étendue d'ensembles biologiques écologiquement distincts, l'adaptation aux conditions locales est accomplie par le développement de différents modèles de comportement. Ces modèles peuvent être envisagés comme s'étant élaborés selon un rythme identıque à celui des communautés biologiques dont fait partıe la glossine.

Les seuls mécanismes de limitation (dans la mesure où ils concernent les populations et non l'individu) dont on puisse prévoir les résultats sont ceux chez lesquels tout l'écosystème, dont la glossıne est un composant, est détruit ou remplacé par un type sans arbre ou dépourvu d'une faune appropriée ou par les deux. La description de ce type de concurrence des écosystèmes n'esł pas un exercice d'écologie conventionnelle de 
l'insecte, mais est en cette circonstance d'une grande valeur pratique. Les travaux en cours sur le relâcher des mâles stériles, peuvent conduire pour la première fois, à des méthodes de limitation basée sur une organisation prévisıble des populations naturelles.

69-161 RAJAGOPAL (P. K.). - Discontinuiłé apparente dans la relation entre température et taux des échanges respiratoires chez la pupe de tsé-tsé. (Glossına morsitans). An apparent discontinuity in the relation between temperature and the respiratory rate of tsetse pupae (Glossina morsitans). Rhod. J. Agric. Res., 1968, 6 (1) : 59.

Cet article complète une étude de RAJAGOPAL el BURSELL dont l'analyse a paru dans cette revue en 1966 sour le numéro 59. L'auleur montre que entre 5 et $35^{\circ}$ chez une pupe âgée d'un jour, le taux de consommation de l'oxygène est d'autant plus fort que la température est plus élevée avec cependant un palier (taux de consommation sensiblement identique) entre 20 et $24^{\circ}$.

\section{Chimiothérapie}

69-162 TRAIN (C. T.), WHITE (R. G.), HANSEN (M. F.). - Efficacité du coumaphos et du naphthalophos conire les nématodes des agneaux. (Efficacy of coumaphos and naphthalophos against nematodes of lambs). Am. J. vet. Res., 1968, 29 (12) : 2331-35. (Troduction du résumé des auteurs).

Du coumaphos administré à des agneaux naturellement parasıtés, mélangé aux alıments à la dose de $2 \mathrm{mg} / \mathrm{kg}$ de poids vif par jour pendant six jours, a rédult d'environ 84,7 p. 100 le nombre d'œufs trouvés dans les fèces. Le même composé, additionné à l'eau de boisson à la dose de $2 \mathrm{mg} / \mathrm{kg} /$ jour durant 6 jours a dımınué ce nombre de 90,8 p. 100. Le naphthalophos, donné sous forme de breuvage à la dose de $50 \mathrm{mg} / \mathrm{kg}$ de poids vif, a élimıné d'environ 94,7 p. 100 le nombre d'cufs fécaux, et, sous forme de bol à la même dose, 98,4 p. 100 .

Le coumaphos mélangé aux alıments a éliminé Haemonchus à 94 p. 100, comme l'a montré l'examen du contenu gastro-intestınal des agneaux, mais n'a pas agi sur Strongylaides, Trichostrongylus ou Oesophagostomum. L'efficacité du coumaphos contre Ostertagia a été de 51 p. 100 , contre Trichuris de 48,6 p. 100 et contre Nematodirus de 4 p. 100 . Le coumaphos additionné à l'eau de boisson a été actif à 96 p. 100 contre Hoemonchus, d'après la numération des helminthes du contenu gastro-intestinal, et à 59,3 p. 100 contre Ostertagia, à 49 p. 100 contre Nemotodirus, 50 p. 100 contre Strongylordes, 18 p. 100 contre Trichostrongylus, 58,3 p. 100 contre Oesophogostomum, 45, 1 p. 100 contre Trichuris.

Le naphthalophos donné en breuvage s'est révélé efficace à 100 et 95 p. 100 contre Haemonchus et Ostertogia ef à $12,3,50,73,4$ et 35,4 p. 100 contre Nematodirus, Strongyloides, Trichostrongylus et Trichuris. La potion n'a eu cucune action sur Oesophagostomum. Le naphthalophos administré sous forme de bol a éliminé à 100 et 96 p. 100 Hoemonchus et Ostergio. Le naphthalophos, sous forme de bol, a eu une efficacité de $50,3,83,3,79,7,36,5$ et 83,2 p. 100 contre Nematodirus, Strongylordes, Trichostrongylus, Oesophogostomum et Trichuris.

69-163 BENNETT (D. G.). - Pouvoir anthelminthique comparé du parbendazole, du thiabendozole et de la phénothiazine chez des agneaux. (Comparative anthelmıntic efficiencies of Parbendazole. Thiabendazole and Phenothiazıne in Iambs). Am. J. Vet. Res., 1968, 29 (12): 2325-30. (Traduction du résumé de louteur).

Le pouvoir anthelminthique de la phénothiazine purifiée et mıcronisée $(500 \mathrm{mg} / \mathrm{kg}$ de poids vif donnés en breuvage), du thiabendazole $(70 \mathrm{mg} / \mathrm{kg}$ de poids vif donnés en breuvage) et de 3 préparations de parbendazole $(15 \mathrm{mg} / \mathrm{kg}$ de poids vif donnés à 8,0 et 2,7 p. 100 en breuvage et dans l'aimentation) a été évalué chez des agneaux infestés naturellement par Trichuris ovis et Nemotodirus filicollis ef expérimentalement par Hoemonchus contortus, souche Kentucky B. Le pouvoir anthelminthique a été calculé en comparant les numérations de vers trouvés à l'autopsie. Le thiabendazole et les 3 préparations de parbendazole étaient actifs de 98 à 99 p. 100 conire $H$. confortus et la phénothiazine étalt active à 79,6 p. 100 Le thiabendazole étail efficace à 100 p. 100 contre N. filicoliss; le parbendazole (en breuvage à 8 p. 100 ) à 99,9 p. 100 contre $N$. filicollis, mais, en breuvage à 2,7 p. 100 et en préparation dans les aliments, Il était légèrement moins actif. 
La phénothiazine agissait seulement à 39,4 p. 100 contre ce parasite et les numérations de vers ne différaient pas de façan significative de celles effectuées sur les animaux témoins.

Il y avait 74,4 à 85,1 p. 100 de $T$. ovis de moins chez les 5 groupes d'agneaux traités que chez les témoins, mais la différence dans les numératıons n'a jamais été statıstiquement importante.

69-164 BORAY (J. C.), HAPPICH (F. A.), JONES (W. O.). - Essais chimiotherapeutiques dans les fortes infections à Fasciola hepatica immature chez le mouton. (Chemotherapeutical tests for heavy immature Fasciola hepatico infections in sheep). Aust. vet. J., 1969, 45 (3) : 94-96. (Traduction du résumé des outelirs).

L'efficacité de quelques anthelmınthıques reconnus ou nouveaux, évaluée précédemment selon une technıque normalisée, chez des moutons parasités par 200 métacercaires (BORAY et HAPPICH, 1968), a été expérımentée chez des moutons porteurs chacun de 1.000 ou 4000 métacercaires.

Les résultats ont montré que les médicaments essayés à des doses comparables à celles ufilisées auparavant pour des parasitoses peu importantes ont eu une action comparable contre les parasitoses plus sérieuses à la même période.

En conclusion, l'essal thérapeutique normalısé convient pour prévoir l'efficacité anthelminthique possıble contre la fasciolose aıguë

69-165 TAFFS (L. F.). - Tétramisole. Son action sur Oesophagostomum spp. immature ef adulte chez des porcs infestés expérimentalement, et quelques observations sur le cycle évolutif. (Tetramisole. Action on immature and adult Oesophagostomum spp. in experimentably-infected pigs, and some observations on the life hisiory). Vet. Rec., 1968, 83 (16): 404-7. (Traduction du résumé de l'auteur).

L'actıon anthelminthique du tétramisole contre Oesophagostomum spp. immature et adulte a été évaluée au cours d'une épreuve de contrôle sur des pórcs infestés expérimentalement. Seize porcs non parasités, répartıs en quatre groupes, ont été infestés par voie orale avec 30,000 larves d'Oesophagostomum spp. Trols groupes ont reçu par vole orale du tétramisole à $15 \mathrm{mg}$ par $5 \mathrm{~kg}, 16$ et 48 jours après l'infestation : un quatrième groupe n'a pas été traité. L'activité anthelmınthique a été estımée en comparant les numérations des oufs dans les fèces et les cultures et le nombre de vers présents dans le gros intestin à l'examen post-martem 55 jours après l'infestation.

Le tétramisole n'a pas eu d'action contre les larves de 5 jours, mais a agi à 85 p. 100 (écart : 79 à 95 p. 100 ) contre les larves de 16 jours et d̀ 76 p. 100 (écart : 51 à 99 p. 100) contre les vers adultes, une falble corrélation a été observée entre les numérations d'œufs ef les nombres de vers. L'évolution d'Oesophagostomum est discutée à la lumière des observations faltes à la période de prépotence el de production des aufs par les vers.

69-166 CROSSLAND (N. O.), HOPE CAWDERY (M. J.). - Observations préliminaires sur la lufte contre Fasciole hepatica avec le molluscicide N-fritylmorpholine. (Prelıminary observations on the control of Fasciola hepatica with the molluscicide N-trilylmorpholine). Vet. Rec., 1969, B4 (B) : 182-84.

Une expérience faite à Ballinamore (Irlande), avait pour but d'établir l'efficacité du molluscicide $\mathrm{N}$-trity/morpholine dans la lutte contre la transmission de Fasciola nepatica. Le terrain expérimental a été séparé en quatre parcelles semblobles de 0,52 ha par des clôtures.

Deux parcelles ont été traitées avec du N-tritylmorpholıne en avrıl 1967 et les deux autres sont restées sans traitement.

La recherche et la numératıon des mollusques ont servı à évaluer les variations numériques saısonnières des mollusques; des moutons ont été utilisés pour établir les variations saisonnières du nombre de métacercaires dans les pâturages.

A cause du temps sec, le nombre de mollusques et de douves a éfé relativement bas toute l'année. Très peu de mollusques ont été trouvés au printemps et en été, mais leur nombre a un peu augmenté en automne. La récupération des douves à partir des moutons a montré un type saisonnier typique de transmissıon avec une intensité maximale en automne.

Le traitement des pôturages avec le N-tritylmorpholine au printemps a été efficace dans la lutte contre la transmission de Fosciolo hepatica en automne. 


\section{Physiologie - climatologie}

69-167 PANDEY (M. D.), ROY (A.). - Variafions de la fréquence des mouvements cardio-respiratoires, de la tempérafure rectale, de la numération globulaire et du faux d'hémoglobine comme crifères du pouvoir d'adaptation du buffle d̀ un milieu chaud. (Variation in cardiorespiratory rates, rectal temperature, biood haematocrit and haemoglobin as measures of adaptability in buffaloes to a hot environment). Brit, vef. $J, 1969,125$ (9) : $463-71$.

Le pouvoir d'adaptation du buffle aux climats tropicaux est déterminé par l'étude des réactions du système cardio-respiratoire, de la prise de la température rectale, des chiffres de la numération globulaire ef du taux de l'hémoglobine chez des animaux protégés contre ou exposés aux conditions climatiques défavorables de l'été.

De ces observations, il ressort qu'au cours de l'été la température du corps, la fréquence du pouls et de la respiration ne sont pas anormalement élevés chez les animaux surveillés. L'augmentation observée de la fréquence du pouls et de la respiration semble nécessaire et efficace pour maintenir la température du corps dans des limites physiologiques. Toutefois, l'enregistrement kymographıque simuliané de lo respiration ef de la température rectale montre clairement que chez cette espèce, le mécanisme thermorégulateur est influencé par l'action directe des rayons solaires.

Les taux élevés d'hémoglobine qui ont été observés au cours de l'été, sont interprétés comme un indice du pouvoir d'adaptation de ces animaux à un milieu chaud.

69-168 CRANWELL (P. D.). - Fermentation microbienne dans l'appareil digestif du porc. (Micrabial fermentation in the alimentary tract of the pig). Nutr. Abstr. Rev., 1968, 38 (3) : 721-30. (Troduction du résumé de l'auteur).

La littérature concernant la fermentation microbienne dans l'appareil digestif du porc, l'absorption ef l'utilisation consécutives des produits de la fermentafion est passée en revue.

La fermentation a lieu dans toutes les parties de l'appareil digestif du porc é commence dès la première semaine de vie. Les substrats fermentent ef les produits de fermentation dépendent d'un ceriain nombre de facteurs dont les plus importants sont l'âge du porc, le type de ration alimentaire consommée ef la localisation dans l'intestin.

Les glucides, les protéines ef la graisse de la ration peuvent tous subir toute forme d'attaque mıcrobienne mais la fermentation des glucides est la plus consıdérable ef certainement celle qui a le plus d'importance du paint de vue économique.

Le degré, l'endroit et le mécanisme de digestıon de la fraction glucidique de la ration (sucres simples, amidon et cellulose) dépendent surtout de l'âge du porc et du type de glucide.

C'est ainsi que des sucres simples comme le Jactose sant aisément fermentés en acide lactique dans l'estomac des porcs de tous âges.

D'autre part, la fermentation du lactose dans le gros intestin des porcs non sevrés n'est probablement pas aussı importante que chez des porcs sevrés recevant une ration. riche en lacłose, parce que le porc non sevré possède une lactase suffisante pour hydrolyser le lactose dans l'intestin grêle, et ainsi une faible partie seulement de lactose non attaqué atteint le gros intestin.

Les jeunes porcs sont incapables d'hydrolyser complètement certaines graines de céréales dans l'intestın grêle et celles-ci ont tendance à s'accumuler dans le gros intesfin où elles sont décomposées par des bactérıes iodophiles.

De même, l'amidon des pommes de terre crues résisfe à l'hydrolyse enzymatique dans l'intestin grêle et est digéré par dégradation bactérienne dans le gros intestin. D'autre part, l'am!don des pommes de terre cuites et l'amıdon du mais sont facilement hydrolysés dans l'inlestin grêle ef une faıble partie afteint le coecum.

La digestion de la cellulose chez le porc dépend entièrement de l'aclıvité bactérienne dans le gros intestin. La digestıbilité par le porc de la cellulose incrustée est bıen moindre que chez les ruminants. La digestion efficace de la cellulose, par exemple de la pulpe de boıs, semble être lıée à l'établissement d'une flore appropriée et au maintien de cette flore par une alimentation régulière avec un substrat cellulosique. La digestion de la cellulose s'améliore avec l'accroissement de poids et est plus importante chez l'animai adulte.

Les résidus de la fermentation des glucides sont principalement des acides gras volatils et de l'acide lactique, les premiers étanl absorbés au niveau de toutes les parties du système digestif. L'absorption de l'acide lactique reste cependant à démontrer chez le parc. II semble que le porc peut utiliser les acides gros volatiles et l'acide lactique mais leur importance comme source d'énergie resle à élucider. 
69-169 ALONSO (A. N. de), ALONSO AMELOT (F. R.), ALVAREZ (C. M.). - Destruction progressive de la flore ef de la faune du rumen par des altérations du milieu ambiant intrinsèque et ses manifestations chez les bovins. (Destrucción progresiva de la flora y fauna ruminal por alteraciones del medio ambiente intrinseco y sus manifestaciones en bovinos). Revta vef. venezol., 1968, 25 (148) : 265-305.

Le processus ruminal complexe des bovins comprend une série de facteurs avec capacité régulatrice des conditions de vie de la flore et de la faune du rumen, comme le $\mathrm{pH}$, l'humidité, la concentration en ions, l'absorption, etc.

On a remarqué dans certains cas, tels que les convalescences de longues maladies au cours desquelles surviennent des atonies ruminales et des rétentions alimentaires, etc, l'apparition d'un tableau clinique caractérisé par de l'anorexie, de l'asthénie, une hypofonction organique qui se termine invariablement par la mort de l'animal. Aucun traitement classique n'a obtenu de résultat.

On s'est rendu comple que ces cas dépendent d'une modification de la flore bactérienne et de protozoaires du rumen, qui est inhibée et détruite peu à peu par l'élévation du $\mathrm{pH}$ du liquide dans lequel elle se trouve, en conséquence de la libération et de l'accumulation d'ammoniac d'origıne endogène ou alımentaire, protéique ou non protéique provoquée par l'interruption du métabolisme normal et de la réabsorption.

L'étude a été faite d'abord in vitro, sur rumen artificiel, ensuite la démonstration a été faite in vivo sur un animal fistulisé ; on obtient la destruction totale des échantillons de microflore et de microfaune du liquide du rumen en atteignant un $\mathrm{pH}$ de 8,5 et une concentration de $150 \mathrm{mg}$ d'ammoniac par $100 \mathrm{cc}$ de liquide ruminal avec les signes cliniques déjà décrits.

\section{Alimentation - Carences - Intoxications}

69-170 RIVIÈRE (R.). - De quelques sous-produits de cultures dans I'alimentation du bétail tropical. Bull. Soc. Scient. Hyg. Aliment., 1968, 56 (4-5-6) : 123-35.

La plupart des pays africains disposent de sous-produits de cultures ou d'issues d'industrıes alimentaires, en quantité souvent importante, qui pourraient être utılisés avec profit pour améliorer l'alimentation des animaux presque toujours insuffisante. Ces produits quand ils ne sont pas exportés restent, pour la plus grande part, inutilisés.

Les plus importants sont étudiés quant à leur composition chimique, moyenne de plusieurs analyses, et à leur valeur bromatologique approximative, calculée au moyen de tables de digestibilité. Ce sont les principaux tourteaux d'oléagineux, les graines de coton, les issues de rizerie et de meuneries, les drêches et levures de brasserie.

69-171 ADRIAN (J.). - Teneur en tryptophane et en vitamine PP des produits végéfaux alimentaires de l'Afrique intertropicale. Ann. Nutr. Alım., 1969, 23 : 233-53. (Conclusions de l'outeur).

Seules les protéines de feuilles et des céréales, à l'exclusion du mais, sont équilibrées en tryptophane $(1,4$ p. 100 des protéines totales); celles des tubercules, des graines de légumineuses et autres et surtout du maïs accusent un déficit plus ou molns profond en cet acide aminé.

Sur le plan de vitamıne PP, les feuilles sont vraisemblablement les sources les plus intéressantes - leur teneur moyenne en niacıne totale étant de $5,8 \mathrm{mg}$ pour $100 \mathrm{~g}$ sec - à l'exception de la graine d'arachide dont la richesse en vitamine PP utilisable est très élevée (16 mg pour $100 \mathrm{~g}$ de graine). Les autres productions végétales sont nettement plus pauvres et, de plus, pour nombre d'entre elles une fraction notable est dépourvue d'efficacité biologique.

Au total, dans les régions où le fondement de l'alimentation est constitué par du mais ou des tubercules, la déficience en tryptophane et la pellagre sont difficiles à éviter. Pour pallier ce risque on doit surtout encourager la consommation de l'arachide ef de nombreuses feuilles alimentaires - à condition toutefois que leur indigestible glucidique n'entrave pas exagérément l'utilisation digestive de la ration. 
69-172 MISRA (R. K.), RANHOTRA (G. S.). - Influence des niveaux énergétiques sur l'utilisation d'azote de protéine d'arachide-urée par des bovins et des buffles. (Influence of energy levels on the utilization of peanut protein-urea nitrogen by cattie and buffalo). J. Anim. Sci., 1969, 28 (1) : 107-09. (Traduction du résumé des auteurs).

Trois bovins et trois buffles avec fistule du rumen ont été alimentés avec des rotions, isoazotées maıs de teneur énergétique varıable, d'après le plan type du carré latiın $3 \times 3$. La plus grande actıvité protéolytique dans le liquide du rumen de ces anımaux était atteınte deux heures environ après l'ingestion et correspondaıt aussi à la multiplication microbienne maximale. L'accroıssement du niveau énergétique utilısable par les animaux a augmenté l'efficacité d'utilisation de l'azote ammoniacal provenant de la protéine d'arachıde-urée alimentaire. Les buffles, contrairement aux bovins, présentaient des conditions dans ie rumen qui étaient plus protéolytiques et aussi plus favorables à l'utilisation de l'ammoniac.

69-173 GARTNER (R. J. W.), ALEXANDER (G. I.), BEWG (W. P.). - Fluctuations saisonnières des réserves de vitamine $A$ chez des bovins sur pâłurages non améliorés. (Seasonal fluctuations of hepalic vitamin A reserves in beef cattle grazing unimproved pastures). Qd. J., ogric., anim., Sci., 1968, 25 (4) : 225-33.

Les réserves hépahıues de vitamine A ont été déterminées chez trois groupes de bceufs, vaches et veaux alimentés sur pâturages deux années consécutives.

Chez les veaux, des différences entre les différents groupes étaient probablement dues à l'âge.

La première année, la concentration moyenne du foie $(\mathrm{mg} / \mathrm{g})$ de 18 vaches et 30 veaux étalt respectivement de $232 \pm 11$ et $96 \pm 3$. La seconde année, les niveaux respectifs pour 26 vaches et 26 veaux étaient de $281 \pm 11$ el $86 \pm 3$. Les taux étaient plus bas en été qu'en hiver.

Il y avait une répétabılité très sıgnıficative du taux de vitamine A pour chaque animal.

Toutes les vaches avaient des réserves suffisantes de vitamine $A$. Les auteurs pensent que les niveaux sub-optimaux trouvés chez 5 jeunes veaux étcient dus d̀ une capacité réduite naturelle à retenır la vitamine A qui n'avait pas d'effet sur leurs performances.

\section{Pâturages - Plantes Fourragères}

69-174 WALKER (B.), SCOTT (G. D.). - Expérimentations des pâtures à Ukiriguru, Tanzanie. I. Comparaisans des systèmes de pâture continue et en rofation sur pâturages naturels de sols argileux. (Grazing experiments at Ukiriguru, Tanzania. I. Comparisons of rotational and continuous grazing systems on natural pastures of hardpan soils). E. afr. agric. for. J., 1968,34 (2) : 224-34. (Traduction du résumé des auteurs).

Deux expérimentatıons ont été effectuées sur des pâtures de sols argileux à Ukiriguru, de 1960 d̀ 1964 .

Au cours de la premıère expérimentalıon, à raisan de 0,96 ha par bouvillon, le total des gaıns de poids moyens obtenu pour 26 mois sur pâturage naturel en système continu, en rolation ef en rotation aver réserve, élat de $\simeq 194 \mathrm{~kg}, \simeq 125 \mathrm{~kg}$ et $\simeq 142,6 \mathrm{~kg}$ ef sur pâturage à chloris gayano en rotation, à raison de 0,86 ho par bouvillon, de $\simeq 146 \mathrm{~kg}$.

Dans la seconde expérimentation au même endroit, à un faux de charge de 1 ha, les gaıns de poids moyens pour 17 mols éfaient de $135,9 \mathrm{~kg}, 109 \mathrm{~kg}$ et $132 \mathrm{~kg}$ pour une pâture en continu, en rotation, ef en rotation avec réserve sur pâturage naturel.

La pâture continue donnait un pâturage à herbe courfe dominé principalement par Bothriochioo insculpto et avec une extension moindre par Ponicum infestum tandis que la pâture en rotation donnalt de l'herbe haute contenant plus de P. infesfum et Hyporrheria spp. el moins de B. insculpto

II est suggéré que ces différences dans le gain de poids vif étaient dues à l'action des différentes charges de pâture sur la quantıté, la disponibılıté el la compositıon chimique des pâturages, aussi bien que les madifications dans la composition botanıque provoquées par ces traitements.

Cependant, bıen que les résultats de ces deux expérimentations aient été peu concluants, iis ont démantré la nécessité d'autres travaux pour détermıner la relation entre les systèmes d'aménagement des pâtures à des charges plus élevées. 
69-175 WALKER (B.). - Expérimentations des pâtures à Ukiriguru, Tanzanie. II. Comparaisons des systèmes de pâture continue ef en rotation sur pâturages naturels de sols argileux en utilisant une forme de changement au carré latin pour une période supplémentaire. (Grazing experiments at Ukiriguru, Tanzanıa. II. Comparisons of rotational and continuous grazing systems on natural pastures of hardpan soils using an « extraperiod latin-square change over design »). E. afr. agric. for. J., 1968, 34 (2) : 235-44. (Traduction du résumé de l'aufeur).

Dans ces séries d'essais de pâture de la secande expérimentation sur pâturages naturels de sols argileux à Ukiriguru, le système de rotatıon s'est révélé meilleur que la pâture continue, d̀ la charge de 0,6 ha par bouvillon, toute l'année sauf durant la fin de la saison sèche et le début de la saison des pluies.

Pendant cette dernière, on a remarqué que les bovins perdaient moins de poids lorsqu'ils pouvaient s'alimenter sur toute la surface du pâturage plutôl que sur une partıe restrente.

Les bouvillons, alimentés en système continu sur pâturage à herbe haute, se portent mieux que ceux alimentés sur pâturage à herbe courte pour les trols premiers essais. Pour les trois autres essais, les résultats des deux types d'alimentation se ressemblaient bequcoup.

Les résultats de ces essais sont discutés, en même temps que ceux de deux expérimentations précédentes effectuées à des charges de 0,96 ha et 0,8 ha par bouvillon.

Les différents résultats obtenus sont dus apparemment à l'inter-relation de la charge et des systèmes d'aménagement des pâturages. Là oủ le degré de pâture était bas, la pâture continue était favorisée, mais lorsqu'll était élevé, la pâture en rotation donnait le meilleur gain de poids vif par demi-hectare et par tête.

On pense que cette relation est due à l'action des différents degrés de pâture sur le rendement en matière sèche et la leneur nutritive des pâturages, autant qu'aux différences dans la composition botanıque.

69-176 WALKER (B.), SCOTT (G. D.). - Expérimentation des pâtures à Ukiriguru, Tanzanie. III. Comparaison de trois charges sur Ia productivité et la composition botanique des pâturages naturels de sols argileux. (Grazıng experiments at Ukiriguru, Tanzania. III. A comparison of three stocking rates on the productivity and botanical composition of natural pastures of hardpan soils). E. afr. agric. for J., 1968, 34 (2) : 245-55. (Traduction du résumé des auteurs).

Les auteurs ont décrit deux expérimentations, au cours desquelles la production animale obtenue à partir de trois types de charges de 0,60 ha, 1,2 ha et 2,4 ha était comparée.

Ces expérimentations ont débuté le 6 février 1963 ef étaient achevées le 12 décembre 1966.

Elies ont montré qu'à des charges fables correspondait un gain de poids plus important par tête qu'avec des charges élevées. Cette différence est attribuée au fait qu'il y a plus de pâfurage disponible de meilleure qualité avec des charges plus basses.

Cependant, durant environ huit mois de l'année, le gain de poids le plus élevé par demi-hectare est obtenu avec la charge de 0,60 ha par tête; du milieu de la saison sèche à la $8^{e}$ semaine de saison des pluies, le gain y est alors inférieur à celur des charges légères.

Les études botaniques ont montré que les degrés de charge élevée utilisés dans ces expérimentations n'exerçaient pas une influence défavorable sur la composition botanique.

En conclusion, sur les pâturages naturels de sols argileux, les charges élevées seraient le moyen le plus économique pour l'élevage des boufs de boucherie.

69-177 MORRISON (J.). - Herbes et légumineuses de haute altitude en Afrique tropicale. (Grasses and legumes at high altitudes in tropical Africa). Herb. Abstr., 1969, 39 (2):101-06. (Traduction des conclusions de l'auteur).

En Afrique tropicale, il existe un excellent potentiel pour la production de pâturages en hautes altitudes. La valeur des pâturages indigènes est médiocre et ceux-ci ne donnent pas de réponse valable à I'amendement. L'amélioration de la production de pâturage et de la qualité des herbages peut être réalisée en introduisant de meilleures herbes et légumineuses et en rectifiant les carences nutritives.

Une surface considérable de pâturage naturel recouvre une terre qui est trop en pente pour la mise en culture et d'autres recherches sur les méthodes pratıques d'amélioration sont nécessaires. 
La production de matière sèche à partir d'herbe fertilisée avec de l'azole et de praırıes composées d'herbes et de légumıneuses ındique que des capacités de charge allant jusqu'à 2,5 tête/ho seraient possibles, mais des essais de production anumale sont nécessaires pour confirmer les résultals des essais agronomıques. Comme le coût des engrais est élevé et les prix du bétail bas en comparaison avec ceux des pays développés, les légumineuses peuvent offrir un moyen économique d'amélioration de la production de pâturage. L'utilisalıon d'engrais azoté évite un grand nombre de problèmes d'aménagement liés aux praıries herbes/légumineuses, maıs leur emploı dépend de facteurs économıques.

Le problème principal eșł le manque de nourriture de haute qualité durant la saison sèche. Une augmentation de production durant la saison de crolssance avec une intensification de la production anımale rendra ce problème plus aigu.

Bien que les sorghos fourragers (en dessous de $2.400 \mathrm{~m}$ ) et l'avoine puissent être utılisés in situ ou comme ensilage durant la saison sèche, l'utilisation d'alıments conservés ou de récoltes de saison sèche n'a pas encore été pleinement étudiée.

Les pôturages amélıorés ne sont possıbles et économiques que dans les régions à systèmes de culture planıfiés, qui ont des élevages productifs de bétall pouvant utiliser de l'herbage de haute qualıté et un marché organısé des productions anımales. Cette situation exıste dans les régıons de haute altitude du Kenya où l'intérêt de l'amélioration des pâturages est associé au développement de l'élevage laıtier et de celui des ovins. cale.

On rencontre de tels faits dans d'autres régıons de houte altitude d'Afrıque tropı-

\section{Zootechnie}

69-178 NEGI (G. C.), BASU THAKUR (A. L.). - Age au premier agnelage du mouton Rampur Bushahri et du premier croisement Rampur Bushahri $\times$ Rambouillet. (The age at first lambıng in Rampur Bushahri and Ramboulliet Rampur Bushahri first cross sheep). Ind. vet. J., 1968, 45 (12) : 1026-30.

L'âge au premier agnelage a élé éfudié chez cent quatre moutons Rampur Bushahri ef trente-huit Rambouillet améliorés.

La moyenne, les extrêmes observées, l'erreur slandard pour chaque race sont consignées dans un tableau. L'âge moyen en jours pour les Rambur Bushahri étaıt de 741,86 $\pm 1,8$ et pour las Rombouillet améliorés de $734,80 \pm 2,3$.

La différence de ces moyennes : 7,06 jours s'est révélée significative. La distrıbution de fréquences pour ces races a été représentée dans un polygone de fréquence.

69-179 BALLICO (P.). - Considérations sur les possibilités zootechniques des zones riveraines du sud-ovest de Ia Zambie. Riv. Agr. Sub. Trop., Firenze, 1968, 62 (4-6) : 145-58.

La région de la Zambie étudiée comprend la basse plaine qui côtoie le Zambèse et qui s'étend, tout en l'incluant, le long de la berge septentrionale du lac de Kariba. Après avoir étudié les caractéristiques climaliques, agronomiques et humaines du milieu, l'auteur consıdère la composition actuelle du cheptel ainsi que les formes d'élevage en relation avec les conditions sanitaires ef les pâturages. Pour conclure, Il affirme que l'établıssement d'un plan d'amélioration progressif prévu pour les dix prochaines années peut permettre d'espérer un élevage de bovins, mais aussi d'ovins. de caprins et de porcs. Cependant il faut affronter en premier lieu le problème humain et en particulıer celuı de la formation du cultivateur de la Zambie qui doit être habitué à des formes d'agriculture et de zoolechnie plus évoluées.

69-180 SADA (J.), VOHRADSKY (F.). - Aptitude Iaitière ei teneur en beurre relatives à la génération $F_{1}$ de bovins indigènes Jersey $\times$ races indigènes du Ghana. Beitr. Trop. Subtrop. Land. Tropen vet. med., 1968, 6 (1) : 63-69.

L'animal qui présente la melleure aplifude laitière, est Jersey/Gudale $F_{1}$, ce qui est dû à sa taille et à son poids. Cette vache est tout à fait différente des deux autres croisements et représente une classe à part. C'est pourquoi le nombre de générations Jersey/Gudale $F_{1}$ devrat être augmenté.

Les auteurs montrent que la Jersey/N'Dama $F_{1}$ est meilleure que la Jersey/Short- 
horn $F_{1}$ quant à l'aptitude laitière, mais la dernière est plus équilibrée que la Jersey/ N'Dama $F_{1}$ en ce qui concerne l'aptitude laitıère, la teneur en beurre et la conformation du corps. Les deux croisements sont propres à d'qutres croisements, rétro-croisements et croisements transversaux.

69-181 WILLIS ( M. B.), PRESTON (T. R.). - L'amélioration génétique des bovins pour la production intensive de viande. (El mejoramiento genetico del ganado bovino para la produccion intensiva de carne). Revta cubana cienc. agric., 1968, 2 (1) : 1-45.

L'auteur passe en revue les méthodes de sélection à utiliser pour améliorer le bétail de boucherie : évaluation généalogique, tests de comportement au point de vue de la nutrition, des conditions d'élevage, du poids, évaluation de la descendance, sélection des femelies, II étudie ensuite l'influence du milieu sur la génétique : influences physiques (température, lumière, logement, maladies...), maternelles, de la population, facteurs économiques. Les méthodes d'élevage font appel au recensement, d̀ l'évalua. tion des races, et à leur amélıoration, à l'hétérosis dont les résultats sont vérifiés d'après la mortalité des veaux, le poids à la naissance, la croissance avant le sevrage et le poids au sevrage, et enfin aux croisements.

En conclusion, l'auteur préconise l'utilisation à grande échelle des méthodes d'amélıoration génétıque sur le plan national et non plus partıculıer.

\section{Chimie biologique}

69-182 PETIT (J. P.). - Détermination rapide chez le chien ef le lapin de l'urée ef du glucose sanguins ef urinaires. Rev Elev. Méd. vét. Pays trop., 1969,22 (3) : 417-22.

L'expérimentation biologique utilise de plus en plus d'animaux, mais leurs normes bıologiques restent souvent mal déterminées, empêchant une interprétation correcte des résultałs.

C'est pourquoi, une méthode semi-quantitative rapide de détermination de l'urée ef du glucose au moyen de bandeleltes est proposée et testée quant à la valeur qu'on peut luı attribuer. Dans le cas de chiens et de lapins, Il s'avère que la précision abtenue est suffisante pour permettre un tri rapide des animaux aples à l'expérimentation. Les résultats d'une comparaison de certaıns taux de glucose obtenus par un dosage enzymalıque classique indiquent clairement qu'on peut substituer la méthode des bandelettes au dosage habituel, les moyennes obtenues par les deux méthodes ne diffèrent que de 1,5 à 1,66 p. 100 .

69-183 QUEVAL (R.). - Ełude électrophorétique des protéines sériques d'herbivores et d'aiseaux de la faune tchadienne. Premiers résultats. Rev. Elev. Méd. vét. Pays trop., 1969, 22 (3) : 409-15.

L'analyse électrophorétique des constıtuants protıdıques du sérum d'animaux sauvages et de leur mobilité relative a été réalısée sur 26 genres zoologıques comprenant 119 sérums de mammifères et 74 sérums d'oiseaux appartenant à la faune cynégétique tchadienne.

69-184 REUSE (J.). - Les groupes sanguins dans la race bovine d'Hérens. Schwetzer Arch. Tierhetk., 1969, 111 (7) : 381-98. (Conclusion de l'auteur).

Après un bref historique de la race d'Hérens, nous avons décrit les méthodes de calcul de la fréquence des gènes. Les groupes sanguins de 249 bêtes (20 taureaux, 113 vaches et 116 descendants) ont été analysés, 65 allèles on été identifiés au locus $B$. Les fréquences géniques ont été calculées dans chaque système (sauf au locus C); les phénogroupes les plus fréquents sont, hormıs l'allèle récessıf,

$$
\left.P Q E_{2}^{\prime}\right|^{\prime}, P I^{\prime}, G Y_{2} E_{1} A_{1}^{\prime} D^{\prime} B^{\prime} \text {. }
$$

Comparés aux autres races suisses, les groupes sanguins de la race d'Hérens présentent des divergences autant quantılatives que qualıtatıves; I'ısolement génétıque de la race est évident. Les tableaux 6,7 et 8 donnent les fréquences de différents gènes dans les races suisses. 
Le degré d'homozygoile $\left(C_{a}\right)$ a été déterminé pour chaque race. La valeur de $C_{a}$ en race d'Hérens est de 0,050 ; ces résultats indiquent une variabilité génétique relativement forte.

Le sondage effectué définit l'état de la population avant la pratique de l'insémination artıficielle; des sondages ultérieurs permettront de suivre l'évolution génétique de la race.

\section{Divers}

69-185 BALLICO (P.). - Instruction ef centres de recherches agricoles : formes de coopération et d'assistance plus modernes aux pays africains en voie de développement. (Istruzione e centrı dı ricerca agrarıa : forme più̀ maderne di cooperazıone e di assistenzo ai paesi africani in via di sviluppo). Riv. Agric. subtrop. trop.. 1969, 63 (1-6) : 212-21.

L'auteur a observé que les résultats obtenus par notre Pays dans le domaine de l'assistance technique agricole aux pays en voie de développement sont insuffisants. II propose que les moyens financiers à la disposition du secteur agricale et zootechnique soient réservés à des interventions en mesure d'apporter une contribution importante au problème du sous-développemenl, c'est-à-dire à l'organisation d'écoles d'agriculture el à la constitution de centres de recherches expérimentales.

69-186 FUNAIOLI (U.). - L'importance des animaux sauvages dans l'utilisation des terres dans certains pays africains arides ét semi arides. (L'ımportanza degli animalı selvatıci neli'uso della ferra di certi paesi aridi e semi-aridi africani). Riv. Agric. subtrop. trop., Firenze, 1968, 62 (10-12) : $400-28 ; 1969,63(1-6) ; 3-37$.

D'ımmenses zones de l'Afrique doivent être considérées actuellement, ef peut-être pour toujours, comme économiquement marginales en ce qui concerne l'activité agricale et zootechnique. Par contre une riche faune y prospère, capable d'utiliser les maigres ressources vitales avec des rendements élevés, laissant en même temps inchangé l'équilibre sol-végétation, très important pour les pays arides.

Ces dix dernières années, de nombreux chercheurs se sont consacrés à l'étude de l'exploitation de la grande faune, surtoul les ongulés, comme forme d'utilisation des terres pour alierner avec l'élevage traditionnel.

Après examen des études et des expériences effectuées en différents endroits de I'Afrique à ce sujet, l'auteur étudie les diverses productions que l'on peut tirer de la faune sauvage (viande, ivoire, peaux, industrie touristique, etc..) et leur importance dans l'économie de quelques pays africains, surfout de l'Afrique Orientale. Il en résulte que, en de nombreux cos, les animaux sauvages peuvent assurer des revenus supérieurs par unité de surface à ceux de l'élevage, et le tourisme qui en dérive peui représenter une source d'entrée de devises de très grande importance. Leur exploitation rationnelle prendra donc une forme de plus en plus précise dans le développement économique de différents pays africains.

69-187 VOS (A. de). - Protection de la faune indigène en Afrique Orientale. Nouveau point de vue sur I'utilisation des terres. Spon, 1969, 12 (1) : 21-24. (Résumé de l'auteur).

En Afrique, la protection des animaux sauvages a une double motivation : tout d'abord, c'est une attraction touristique de premier ordre, ensulte, elle peut être une source utile de protéınes. L'explosion démographique exige une agriculture intensifiée incompatible avec la protection de la faune sauvage; l'auteur estime essentiel de metire sur pied un plan précis pour l'avenir de ces animaux. II pense qu'il est plus facile de les protéger sur des lerres à faible potentiel agricole et préconise la création de zones tampons situées entre les réserves zoologiques ef les zanes habitées à agricuiture intensive, dans lesquelles le gros gibier serait partiellement protégé.

69-188 BROWN (M. L.), WORTH (R. M.), SHAH (N. K.). - Habitudes ef consommation alimentaire au Népal. (Food habits and food intake in Nepal). Trop. geogr. Med., 1968, 20 (3) : 217-24. (Traduction du résumé. des auteurs).

Les auteurs ont réalısé une étude diététique en notant les différents aliments ingérés en 24 heures dans 957 familles de 19 villages du Népal. Ils ont interrogé les famılles au sujet des repas pris la veille. Ils ont obtenu de plus des informations sur les coutumes 
alımentaires, en parhiculier durant la gestation ef la première enfance. La consommation moyenne d'aliments par tête variait beaucoup dans les différents villages, maıs en moyenne l'apport de calories et de proténes étaıt plus élevé que celui qui est décrit dans d'autres régions d'Extrême-Orient. Les céréales fournissent pratiquement toutes les protéines de la ration. L'apport de calcıum, de riboflavine et de vitamines $A$ ef $C$ était faible maıs il a vraisemblablement été sous-estimé étant donné la disponibilité saisonntère de fruits et légumes, capables de fournir des compléments de ces principes nutritıfs. L'absorption de thiamıne ef de niacine était en général satısfaisante, car les graıns de céréales sont consommés, en grande partie, entiers.

Les aliments les plus appréciés durant la geslation étaient du « dal », de la viande et du rız. En général le lait et les produits laitiers n'étaıent pas très appréciés.

L'alımentation des enfants dépendaif de la casle. Les Baisyas, caste prédominante au Népal, nourrissent les enfants au lait maternel plus longtemps et ajoutent d'autres aliments à un âge plus avancé que les autres castes. Les mères Baisyas ont tendance à préférer le riz combıné à des aliments de plus grande valeur protéique comme aliments complémentaires. D'autres castes ont une préférence pour le riz ou le pain en tant qu'alımentation appropriée pour complérer l'allaitement.

\section{Bibliographie}

69-189 LÉPINE (P.), GAMET (A.). - La rage. Paris, L'Expansion (15, rue Saint-Benort, 60), 1969. 140 p. 27 fig. (Coll. : Maladies animales à virus). $\operatorname{PrIx}: 23 \mathrm{~F}$.

A l'heure où la rage, qui n'a jamais disparu dans le reste du monde, devient à nouveau d'actualité dans une Europe Occidentale gagnée par l'avance inexorable de l'enzootie vulpıne, une étude d'ensemble du problème de la rage et de sa prophylaxie s'imposait tout partıculièrement : le lıvre de P. LÉPINE et A. GAMET répond opportunément d̀ cette attente et vient combler une lacune dans la documentation vétérinaire et médicale contemporaine.

Après une brève revue des notions classiques, toujours valables mais aujourd'hui dépassées, les auteurs, dont il esł superflu de rappeler la longue expérience du sujet, exposent de façon concise et claire les notions nouvelles qui se sont imposées sur la hature du virus rabique, sur sa morphologie, sur son écologie et sa transmission. Le diognostic, l'anatomie pathologıque, les méthodes de coloration et la microscopie en immunofluorescence sont développés avec toutes les précisions nécessaires. Enfin le traitement anti-rabique entièrement rédıgé à la iueur des acquisitions les plus récentes, expose dans le délail la séra-prévention, les différents vaccins et leurs applıcations, suivant les cas, avant ou après infection.

Tel qu'il est conçu, cet ouvrage rédıgé dans l'esprit de la collection sera un guide précieux non seulement pour le vétérinaire mais pour le médecin placé devant la respansabilité de décider ou de refuser un traitement, pour le technicien chargé du diagnostic comme pour le chercheur soucieux de mieux connaître l'un des plus mystérieux et des plus dangereux des virus pathogènes pour l'homme ef les animaux.

L'ouvrage comporte :

- des indications statistiques montrant l'importance et l'extension mandiale de la maladie,

- un rappel historique retraçant les étapes successives de nos connaissances concernant l'agent pathogène, le diagnostic, les traitements et l'épizootologie,

- l'étude virologique résumant les données actuelles sur le virion rabique, sa marphologie, sa constitution chımique, ses caractères, sa culture in vivo, in ovo et in vitro, l'expertıse des souches fixes, la structure antigénique et les.problèmes d'interférence, - l'étude clinique de la maladie chez l'homme ef chez les animaux domestiques et squvages,

- le diagnostic par les techniques d'immunofluorescence, l'histologie classique, les inoculations ef la conduite à tenir vis-à-vis d'un animal suspect,

- l'étude anatomopathologique,

- la pathogénie qu conduit les auteurs à examiner le siège de la virulence rabique chez l'animal enragé, les voies de pénétrafion du virus, sa propagation ef enfin la physiopathogénie de la maladie,

- l'étude du traitement antirabique permet de traiter de la conduite à tenir après morsure chez l'homme et chez l'animal, des soins locaux et des divers schémas de trailements avec élude du sérum el des différents vaccins,

- l'épizootologie réunit l'exposé de la chaîne épidémiologique, la rage sauvage du renard et des chéiroptères, en particulier la rage citadine, 
- le chapitre prophylaxie comporfe l'étude des modalıtés d'actıon sur les réservoirs de virus sauvages el domestıques, la prophylaxie médicale chez l'animal et chez l'homme avec la vaccination préventive avant exposition.

L'ouvrage se termine par une abondante bibljagraphie qui réunit plus de deux cents références permettant de se rapporter aux multiples publications consacrées à un sujet qui présente encore de nombreuses inconnues.

\section{9-190 DEBROT (S.), CONSTANTIN (A.). - Hygiène el production de} la viande. Parıs, Maloine, 1968, 332 p. fig. Prix : 24 F.

Les auteurs ont conçu la matıère de ce livre en fonction des connaıssances théoriques et pratiques utiles à la formation professionnelle des techniciens de l'élevage. Cet ouvrage étudie successivement : I'anatomie, la physiologie, la pathologie, la zootechnie des anımaux de boucherie, la jurisprudence, l'hygıène de la viande et l'hygiène professionnelle, Il servira de manuel pour les différentes spécialités touchant aux productions animales.

69-191 WHYTE (R. O.). - Grasslands of the monsoon. London, Faber and Faber, 1968, 325 p. Prix : 50 \$.

Les terres soumises à la mousson, telles qu'elles sont définies dans ce livre, représentent une proportion significative de la surface du monde, particulièrement en Afrique et en Asie, mass c'est en évaluant leur populatıon humaine et bovine et leur surface de terre cultivée qu'elles revêtent encore plus d'importance.

Bien que l'Asie de mousson ne comprenne qu'environ un septième de la surface des terres du globe, elle contient plus de la moitıé de la population humaine du monde et probablement un tiers de la population bovine et un tiers des terres cultivées.

Depuis que pratiquement tous les pays soumis à la mousson sont dans la catégorie "en développement», leurs ressources naturelles, la voie qu'ils ont utilisée jusque-là et leurs potentialités futures ont une portée internationale.

Ils comportent de vastes élendues qui peuvent être appelées pâturages, dans le sens le plus large, et qui ont en commun avec d'autres types de pâturages tropicaux d'être une grande ressource inutılisée pour le développement de la production du bétal.

L'auteur base sa description de ces pâturages sur son expérience pratique de nombreuses années. II suit une transversale de Dakar au Sénégal jusqu'aux Darlıng Downs dans le Queensland, à travers une trentaine de pays ef expose ce que l'on connait sur leur composition botanique, leur conditıon écologıque et leur valeur économique dans l'apporl de produits anımaux pour les besoins nutritionnels et autres des peuples de la région.

Des questıons de phyta-géographıe et de migration ınter-régionale, de taxanomie et de généfique et les caractéristıques du comportement biologique des plantes poussant en milieu de mousson sont aussı passées en revue.

Avec «milk production in developing countries》, le Dr WHYTE a apporté une contribution importante pour la résolution des problèmes de production alimentaire dans les pays tropicaux et subtropicaux. « Grasslands of the monsoon » augmente encore notre connalssance de cette région critique. 